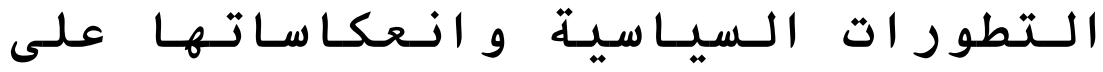

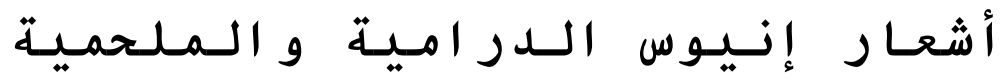 \\ أ. فاتن عثمان
}

كلية الآداب - جامعة الأسكندرية

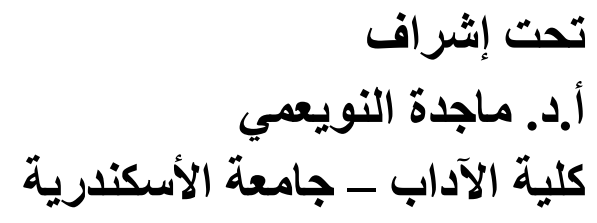

كانت الثقافة الأولى التي نشأ عليها الشعر الغنائي وغيره من الفنون

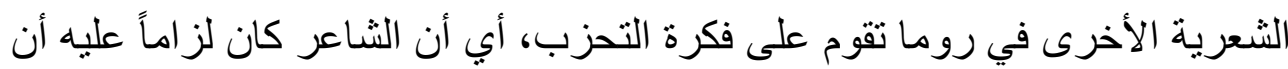

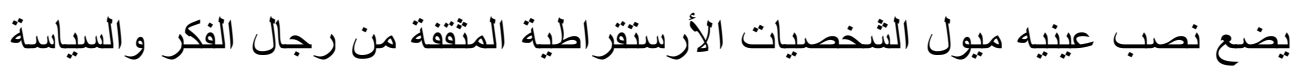

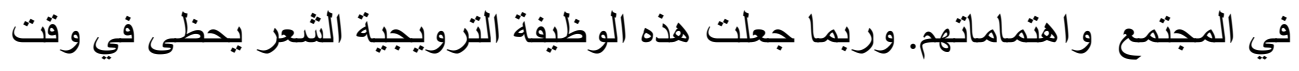
لاحق بمزيد من الاهتمام والترحيب من قبل رجال الدولة الذين تميزوا بالصرامة الدادئ

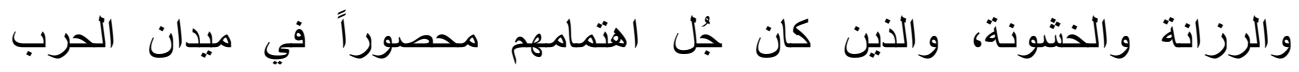

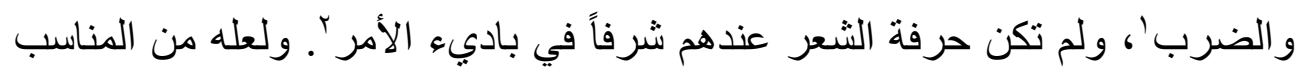

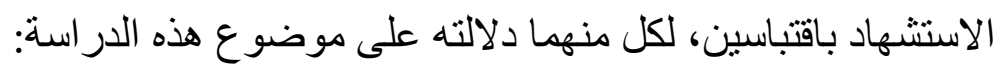

بالنسبة للاقتباس الأول فهو من مؤلف بوركيوس كاتو الرقيب Porcius Cato

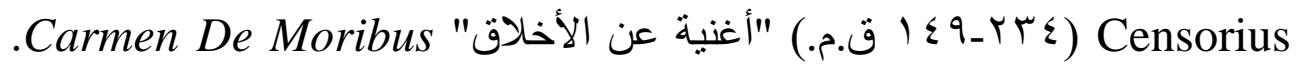

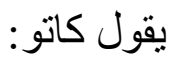

"Poeticae artis honos non erat. Si quis in ea re studebat aut sese ad convivia adplicabat, 'crassator'” vocabatur."4 


\section{فاتن عثمان}

" لم يكن هنالك احتر ام لفن الشعر. فإذا وجه شخص ما اهتمامه لهذا الأمر، أو ألحق نفسه بمآدب العشاء، كان يُطلق عليه صعلوكاً."

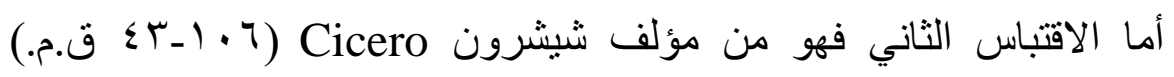
الفلسفي "المناقثنات التوسكو لانية" Tusculanae Disputationes. يقول مول شيشرون:

"Sero igitur a nostris poetae vel cogniti vel recepti.

Quamquam est in Originibus ${ }^{5}$ solitos esse in epulis canere convivas ad tibicinem de clarorum hominum virtutibus." " لذلك حظي الشعر اء إما بالثهرة أو بالقبول بيننا في وقت متأخر. على الرغم

تضمنته "الأصول" من اعتياد الضيوف في مآدب العثاء التغني بمصساحبة عازف الفلوت بفضائل مشاهير البشر \." ومن منطلق هذين الاقتباسين السالفين، تبدأ هذه الدراسة التي تهدف إلى: أ ـ إلقاء الضوء على بعض جوانب من ارتباط الشعر اللاتيني المبكر بالحياة السياسية في روما.

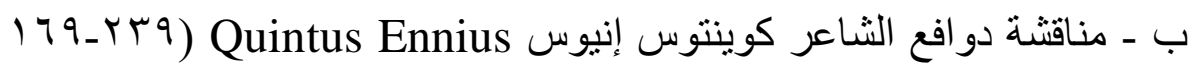
ق.م.) من نظم أشعاره التي تغنت بأمجاد بعض القادة الرومان و إنجاز اتهم، باعتباره أحد رواد الثعر اللاتيني المبكر. من لفعاره.

شهدت الفترة المبكرة من تاريخ الأدب اللاتيني ارتباطاً وثيقاً بالحياة السياسية في روما، وجاء هذا الارتباط في المقام الأول بتاريخ الحملات العسكرية.

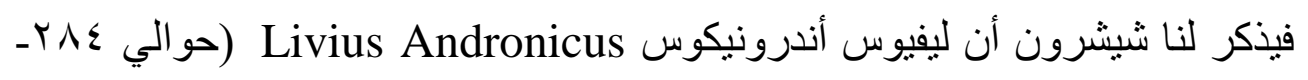




\section{التطورات السياسية وانعكاساتها على أثعار إنيوس الدرامية والملحمية}

حوالي ع •r ق.م.) - شاعر روما الأول - قدم إليها أسيراً في إحدى حروبهاه. كما

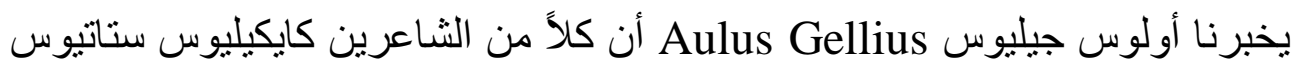
Afer (الأفريقي) Caecilius Statius هار Tentius هذا الارتباط بين الأدب والسياسة عن رعاية أفراد الطبقة الأرستقر اطية التي تقلدات

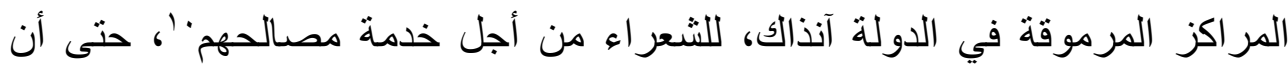

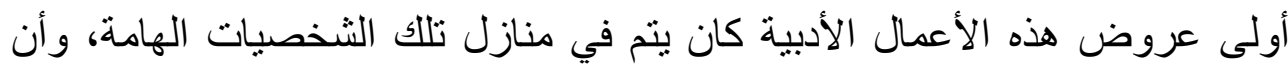
أول جمهور لهذه الأعمال كان من أهل بيتهم. فلم يحظ الثعر بالقبول والثعراء

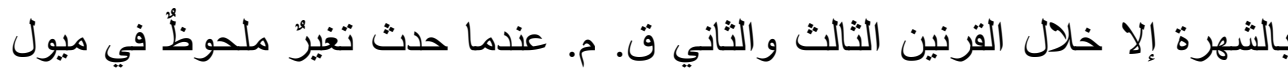

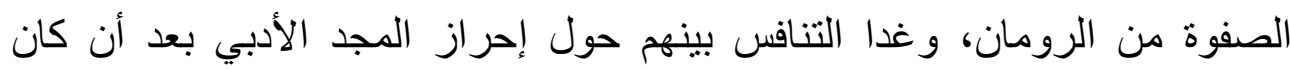

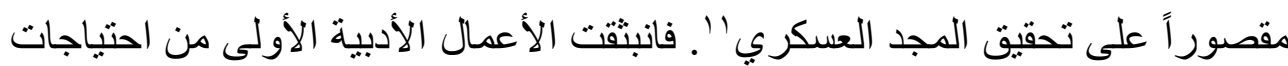

$$
\text { سياسية وصيغت لأغر اض سياسية. }
$$

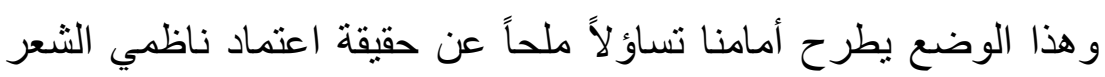

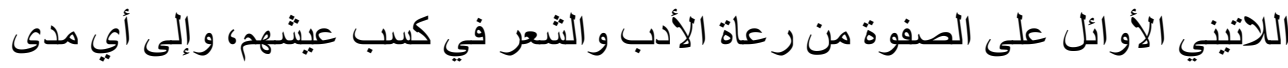

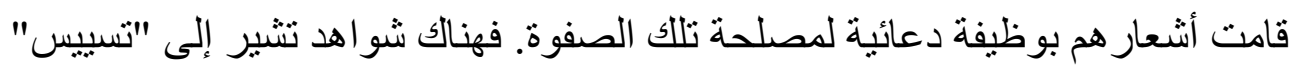

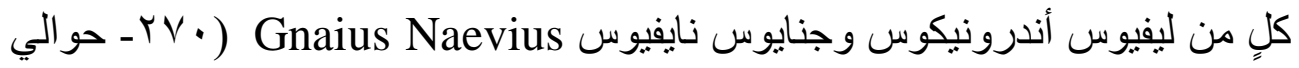

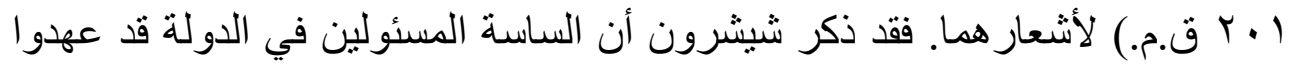

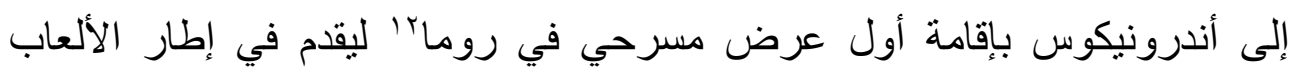

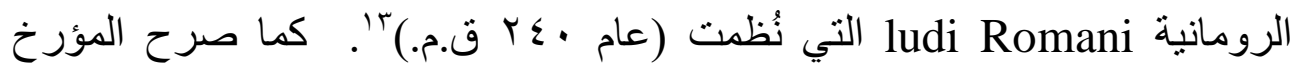

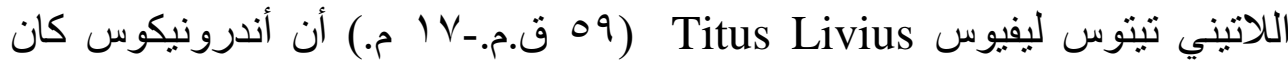

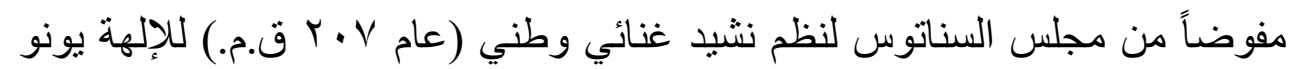
Iuno

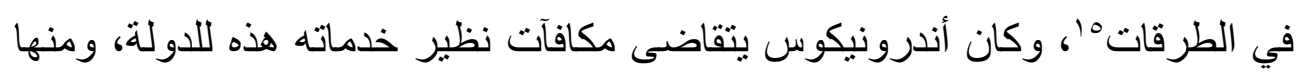




\section{فاتن عثمان}

على سبيل المثال ما منحه مجلس السناتوس له من حق الإقامة الدائمة في معبد ربة الحكمة مينرفا Minerva، هذا إلى جانب الاعتر اف الرسمي من قبل الدولة "بر ابطة الشعر اء" Collegium Poetarum وبحقهم في التجمع، وجعل هذا المعبد مقراً رئيسياً لتجمعهم" أ. وفي هذا الأمر دلالة هامة على ارتباط نشأة الأدب اللاتيني بالحياة السياسية في روما حين أصبحت في مسيس الحاجة إلى وسيلة تروج بها لمشرو عاتها التوسعية وتخدم بها مصالحها المدنية، ومن ثم يتحقق الأمن والاستقرار في المجتمع دئه الروماني. ويخبرنا كاتب السير سويتونيوس Suetonius (9 7ـ-. ع. (م.) أنه كانت توجد وسيلتان أمام أندرونيكوس لكسب الرزق: الأولى إلقاء الثعر اللاتيني الذي كان

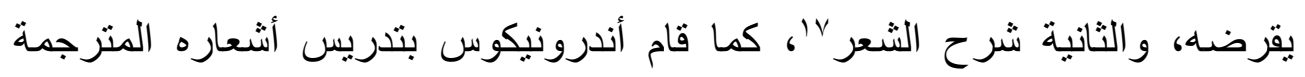

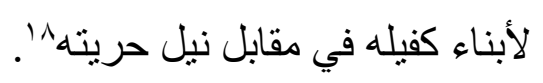

أما بالنسبة لنايفيوس فهناك من الثواهد ما نشير إلى أنه كان شاعراً

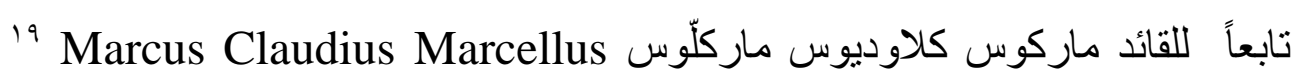
الذي عهد إليه بكتابة الأشعار التي تخلد انتصار اته، فقام نايفيوس بنظم مسرحية تكرمده تسمى " كلاستيديوم" Clastidium •r يتغنى فيها بانتصـار ماركلّوس في بلاد الغال

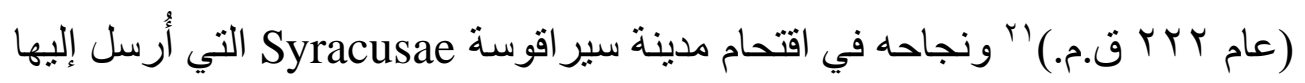

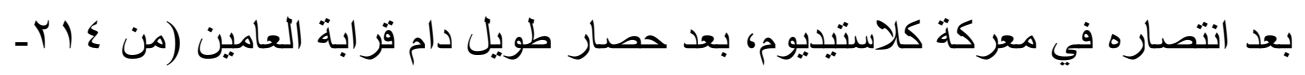

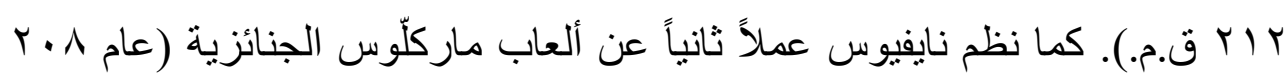

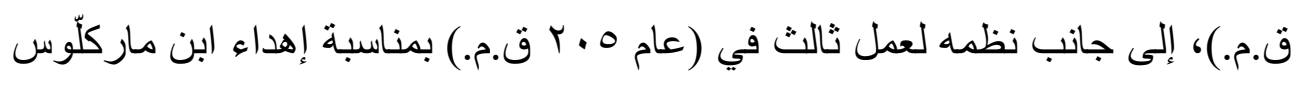

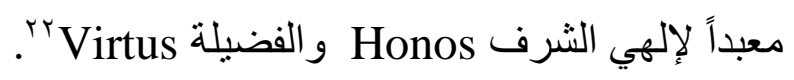
و الجدير بالذكر أن ولاء الثاعر نايفيوس للقائد ماركلّوس وتغنيه بمآثره في

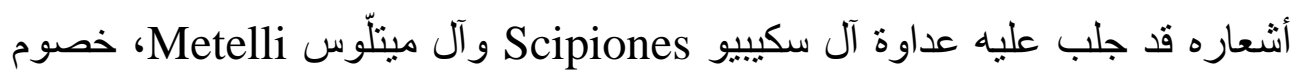
آل ماركلّوس Marcelli المشهورين، مما جلب على نايفيوس متاعب النزاع

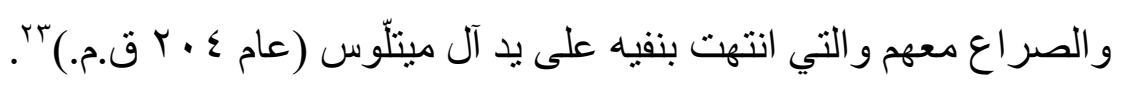


التطورات السياسية وانعكاساتها على أثعار إنيوس الدرامية والملحمية

و إذا كان هذا هو شأن الشاعرين أندرونيكوس ونايفيوس، فماذا عن الثاعر

إنيوس الذي ساهمت الأحداث السياسية في تشكيل أشعاره التي تغنى فيها بمآثر بعض القواد، لاسيما أن إنيوس قد ارتبط بصداقات عديدة مع أبناء الطبقة الأرستقر اطية.

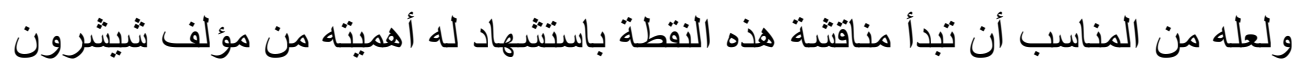
"دفاعاً عن الثاعر أرخياس" Pro Archia Poeta الذي يقول فيه:

"Carus fuit Africano superiori noster Ennius in caelum huius proavus Cato tollitur: magnus honos populi Romani rebus adiungitur. omnes denique illi Fulvii non sine communi omnium nostrum laude decorantur." 24

"كان شاعرنا إنيوس عزيزاً عند [سكيبيو] الأفريقي الأكثر عظمة فقد رفع كاتو الجد الأعظم للسماء، وبهذه الطريقة وهب المجد العظيم

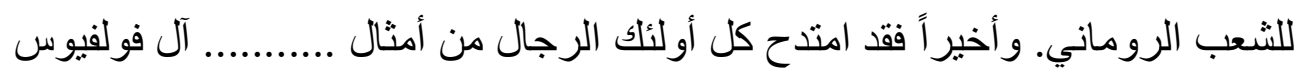
بثناعٍ شارك فيه كل فرد منا بلا استثناء." يأتي في مقدمة الشخصيات المرموقة التي ارتبطت بعلاقة صداقة بالثاعر إنيوس، على نحو ما أوضح شيشرون، القائد الروماني سكيبيو الأفريفي Scipio Africanus العائلات الأرستقراطية في روما، وهي آل كورنيليوس Cornelii الذين اشتهروا بولعهم الثديد بالثقافة الإغريقية، وهذا ما دفعهم إلى رعاية إنيوس طو ال فترة وجوده الهون فى روما. وقد نظم إنيوس على شرف هذا القائد قصيدة غنائية بعنوان "سكيبيو" Scipio

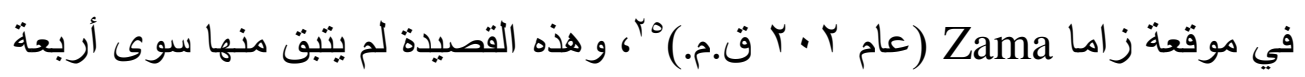
عشر بيتاً يتغنى فيها باستقبال روما لسكيبيو بعد الانتصار قائلاً: 


\section{فاتن عثمان}

[Quantam statuam faciet populus Romanus

Quantam columnam quae res tuas gestas loquatur?] $]^{26}$

$$
\begin{aligned}
& \text { "أي تمثال عظيم سوف يشيده الثعب الروماني، } \\
& \text { و أي نصب تذكاري هذا الذي قد يتحدث عن إنجاز اتلك؟" } \\
& \text { هذا إلى جانب نظم إنيوس "لإبجر امتين" يمجد فيهما القائد ذاته ليحفر ا على } \\
& \text { مقدمة تمثنال له وكذلك على خلفيته. فيقول إنيوس عن سكيبيو في إحدى "إبجر اماته": }
\end{aligned}
$$

"Hic est ille situs

Cui nemo civis neque hostis .......

Quibit pro factis reddere opis pretium."27

$$
\begin{aligned}
& \text { "هنا يرقد هذا الرجل ... } \\
& \text {.... الذي لن يستطيع أي أحد سو اء أكان مواطناً أم عدواً }
\end{aligned}
$$

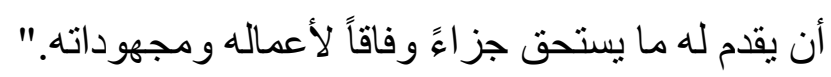

أما كاتو الرقيب فقد تعرف عليه إنيوس أثناء خدمته في الجيش في جزيرة سردينيا Sardinia وجمعتهما صداقة وألفة^r. ومن تناقض الأحداث أن يسترعي إنيوس، الذي كان على اتصال وثيق بالحضارة الإغريقية، انتباه زعيم الحركة المعادية للهلّينية في روما وهو كاتو الرقيبوَ، الذي كان يشغل آنذاك منصب الحاكم المالى quaestor

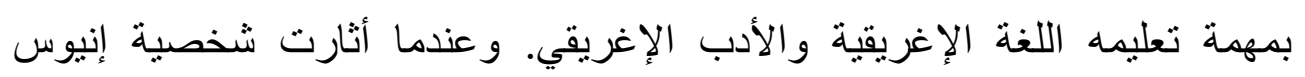

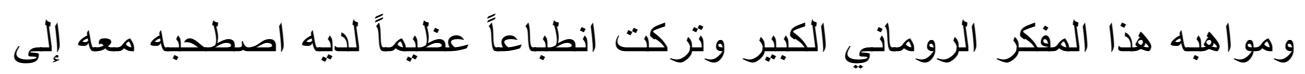

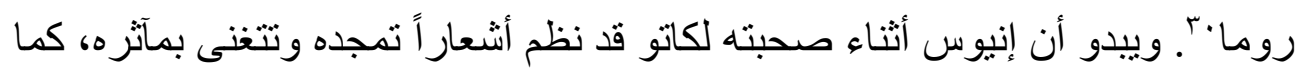
ذكر شيشرون، إلا أنها قد فُقدت. 
التطورات السياسية وانعكاساتها على أثعار إنيوس الارامية والملحمية

ارتبط إنيوس كذللك بصداقة مع القائد الروماني ماركوس فولفيوس

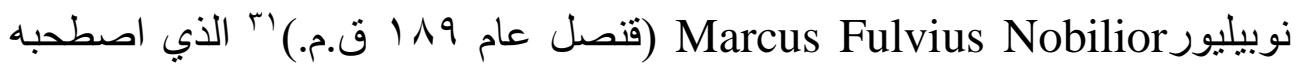

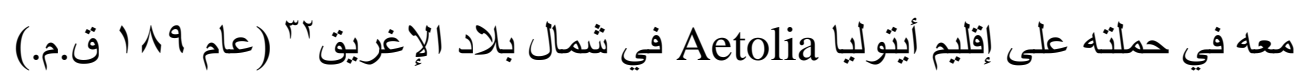

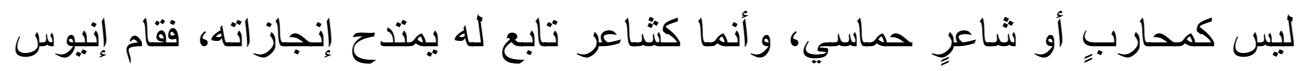

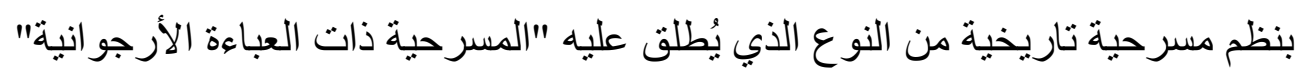
Fabulae Praetextae

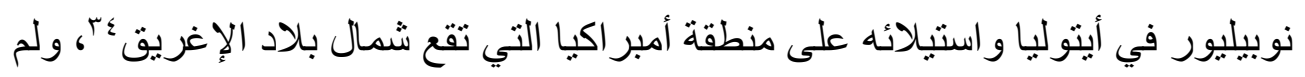

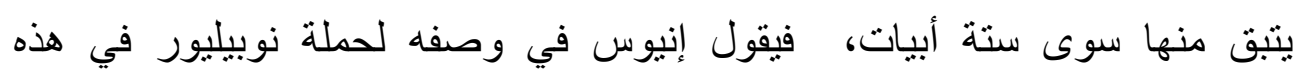

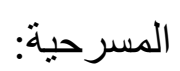
“.......................... Bene mones;

tute ipse cunctato; o vide fortem virum." 35

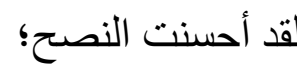

فلتنلكأ أنت بنفسك؛ انظر يالرجل الثجاع"ج"."

كما تغنى إنيوس بمآثر نوبيليور في حملته على إقليم أيتوليا في الكتاب

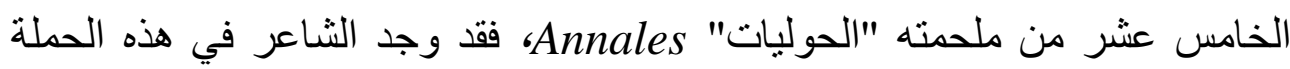

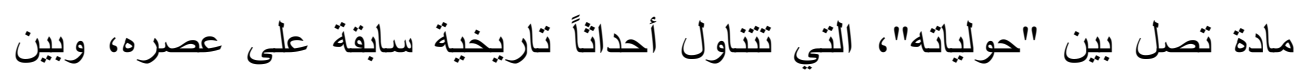

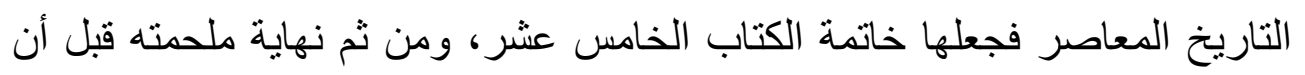

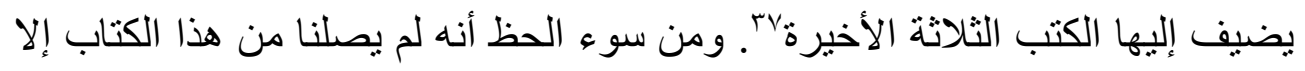
القليل الذي يصف فيه إنيوس حصار نوبيليور لمنطقة أمبر اكيا. فيقول إنيوس:

"Occumbunt multi letum ferroque lapique aut intra muros aut extra praecipe casu." 38 


\section{فاتن عثمان}

$$
\text { سواء أكان داخل الأسو ار أم خارجها في سرعى السيف و الحجارة }
$$

وقد وهب كوينتوس Quintus - ابن هذا القائد النبيل نوبيليور- حقوق المواطنة الرومانية للثاعر إنيوسجّ الذي أصبح منذ ذلك الحين عضواً مؤثراً في الأوساط الأرستقر اطية، وبالتالي أصبح ارتباطه وثيقاً بالثخصيات السياسة. أثنار أمر التحاق إنيوس بحملة القائد نوبيليور حفيظة كاتو الرقيب.؛ الذي كان سبياً مباشراً في شهرة إنبوس، فر اح في خطبة شهيرة له بنتقد بشدة هذا القائد

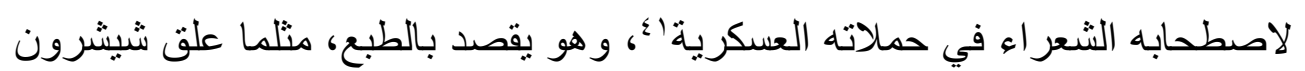
الذي حفظ هذه الخطبة، اصطحاب نوبيليور لإنيوس، حيث اعتبر كاتو هذا التقليد نوعاً

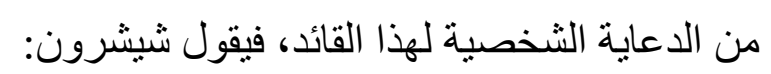

"Honorem tamen huic generi non fuisse declarat oratio

Catonis, in qua obiecit ut probrum M. Nobiliori, quod is in provinciam poetas duxisset; duxerat autem consul ille in Aetoliam, ut scimus, Ennium. quo minus igitur honoris erat poetis, eo minora studia fuerunt." 42 " توضح خطبة كاتو أنه لا يوجد احتر ام في هذا النوع، والتي بنتقد من خلالها ماركوس نوبيليور على هذا السلوك المخزي، من حيث احضاره الشعر اء إلى و لايته، ولكن ذلك القنصل [ أي نوبيليور] قد أحضر إنيوس إلى أيتوليا، كما نعلم، لذلك هلك

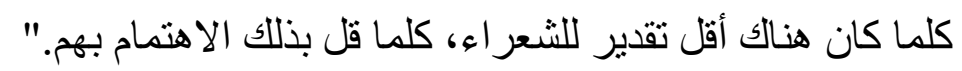

وقد أثارت خطبة كاتو جدلاً واسعاً بين العديد من النقاد حول مدى علاقتها

$$
\text { بأثعار إنيوس الغنائية: }
$$


التطورات السياسية وانعكاساتها على أشعار إنيوس الدرامية والملحمية

- هنالك رأي يقول إن كاتو لم يقصد بهذا الهجوم مديح إنيوس للقائد نوبيليور

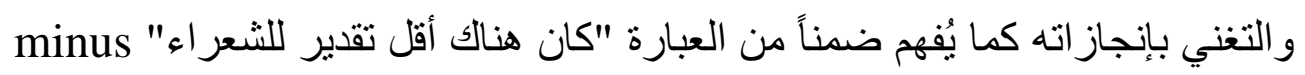
honoris erat poetis

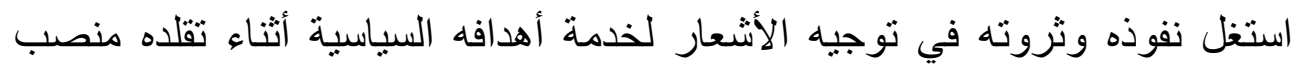

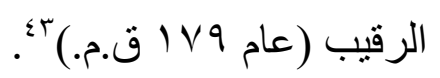

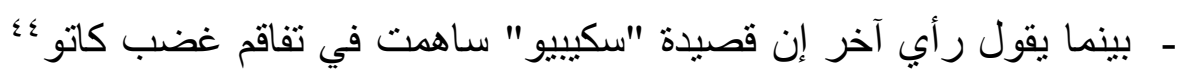

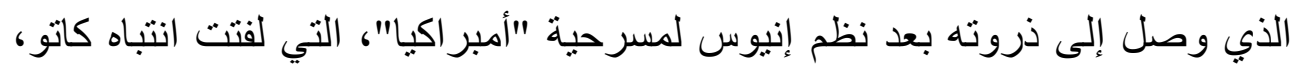

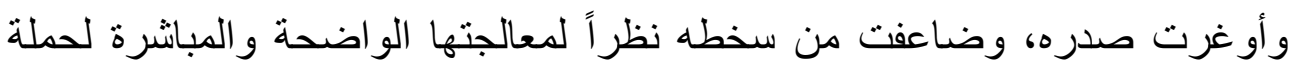

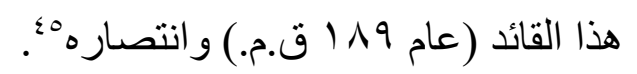

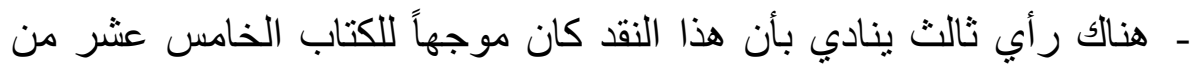

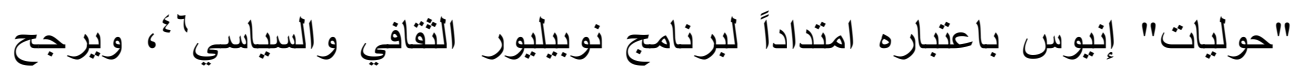
مؤيدو هذا الرأي أن إنيوس هو المؤلف الأصلي لمجموعة المباره القوائم التي نسبها نوبيليور

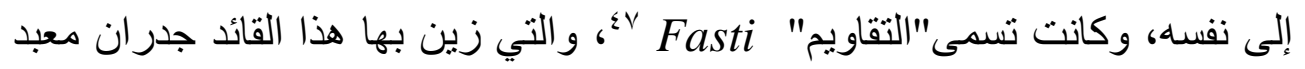

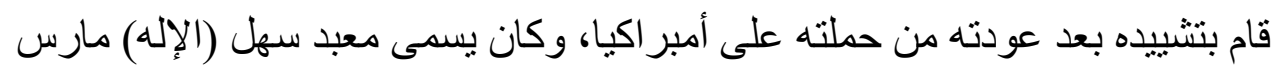
Campus Martius

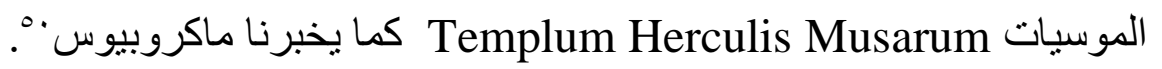

ومن الأمور الأخرى التي تطرح تساؤ لاً حول هدف إنيوس من ور اء مديحه

لبعض القواد ما يعزوه الكاتب الموسوعي بلينيوس الأكبر Plinius Maior (rآ-

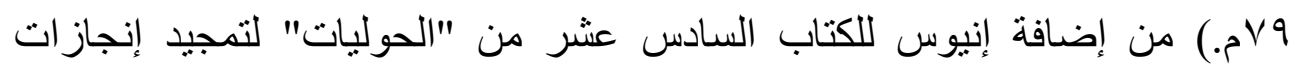

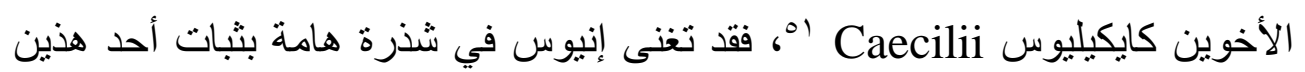

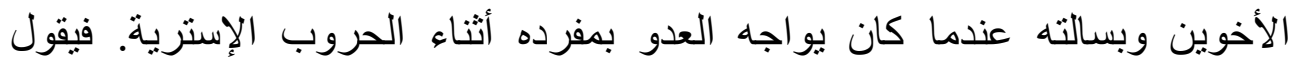
إنيوس: - 20 - n

"Undique conveniunt velut imber tela tribuno: 


\section{فاتن عثمان}

semper abundantes hastas frangitque quatitque;

totum sudor habet corpus multumque laborat, nec respirandi fit copia; praepete ferro

Histri tela manu iacientes sollicitabant." ${ }^{, 52}$

" تتساقط الرماح من كل جانب صوب التريبونوس كالمطر المنهر

كان طو ال الوقت يحاول صد و ابل القذائف وهو يرتجف

وكل جسده يتصبب عرقاً، فقد أنهكه التعب كثثبر آ

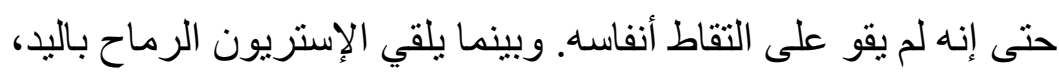

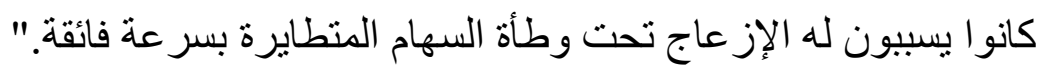

وقد كان الأخوان كايكيليوس نائبين للقائد أولوس مانليوس فولسو Manlius Vulso

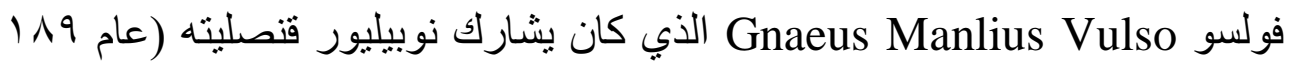
ق.م.)، لذلك يرى البعض أن الإشادة بإنجازات الأخوين كايكيليوس كان من شأنه نانه

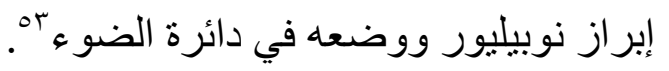

لقد انقسمت آراء النقاد حول هدف إنيوس من نظم أشعاره، ففريق يعتقد في

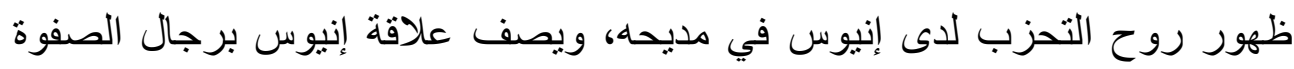

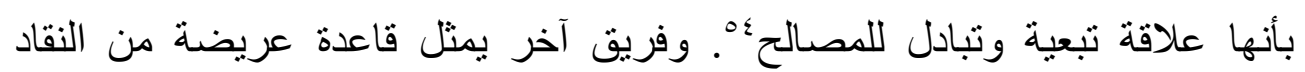

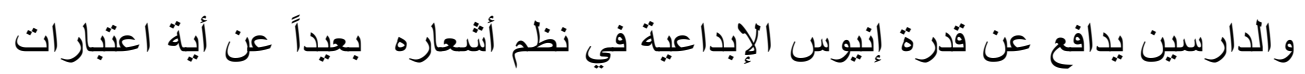

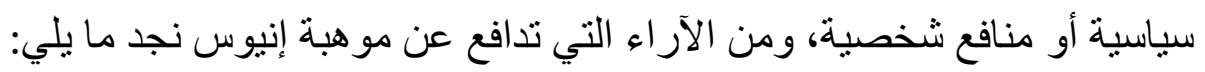




\section{التطورات السياسية وانعكاساتها على أثعار إنيوس الدرامية والملحمية}

- رأي يرى أنه من الصعب تحديد ما إذا كان إنيوس شاعراً تابعاً لبعض القادة الرومان في عصره، لاسيما القائد نوبيليور. فربما يكون رجل الدولة نوبيليور هو من تأثر بالثاعر إنيوس في ابتهاله إلى ربات الفنون الإغريقيات MoŨ بدلاً من ربات الفنون الإيطاليات Camenae، وربما يكون الثاعر إنيوس هو من تأثر بهذا القائد في الحملة التي صحبه خلالها، والتي أسفرت عن نقل تماثيل ربات الفنون الإغريقيات إلى روماءْ، ومن ثم ألهمته هذا الأسلوب الجديد في المعالجة الشعرية، لذلك أياً كان مصدر الإلهام: القائد أم الشاعر، فالحقيقة التي لا يجب إغفالها هي أن الإثنين قد عملا معاً في منظومة متكاملة بكل إخلاص وتفان للعبور بروما نحو إنها الحضارة الإغريقية آنه

- رأي آخر يرى في عبقرية إنيوس الأدبية وموهبته الفطرية في نظم أشعاره، و أسلوبه الفني، إلى جانب تمكنه من أدو اته، و عثقه الثنديد لفكرة البطولة الرومانية، ما جعله بحق رائداً لعصرٍ أدبي جديدٍ. ويلقي صاحب هذا الرأي بظلال من الثك حول اتهام بعض النقاد لإنيوس بالتحزب في مديحه، ويصف إنيوس بأنه "كريم المولد"، "ذو موهبة عظيمة"، ولديه مصدر رزق مستقل، وتلاك أمور كفلت له الحرية و الحياة الكريمة بين الأوساط الرومانية الر اقية دون الحاجة إلى استغلال أثعاره لتحقيق منافع

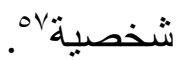

- رأي أخير يعتقد أن نظم إنيوس لقصيدة "سكيبيو" تكريماً للقائد الروماني سكيبيو الأفريقي، إلى جانب ابتهاله إلى ربات الفنون الإغريقيات في عمل أدبي يتغنى بمآثر نوبيليور الذي استولى على تماثثيل ربات الفنون الإغريقيات، وكذللك نظمه

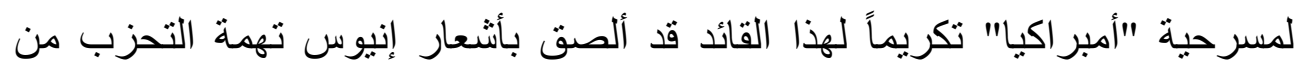
خلال المديح. ويشير صاحب هذا الرأي إلى أنه إذا كان البعض يعتبرون هذا دليلاً على تورط إنيوس في نشاطات هذين القائدين، العسكرية و الدينية، فعلينا ألا ننكر رغم 


\section{فاتن عثمان}

ذللك براعة إنيوس في نظم أشعاره وموهبته الفذة في توظيف الموروث الإغريقي، ليقدم لجمهوره الروماني رؤية جديدة ومتفردة لأسلوبه الشعري ومو هبته الأدبيةهمه لعل هذا الفريق من النقاد قد استمد وجهة نظره عن موهبة إنيوس من محاولة شيشرون تبرئة هذا الثـاعر من تهمة التحزب من خلال مديحه، وتقديم الدفوع

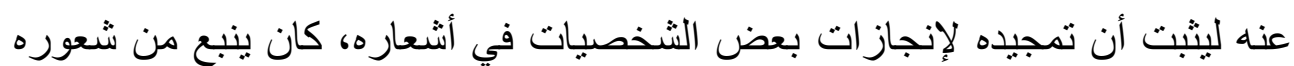
العميق بالوطنية الرومانية، وليس من باب الصداقة و الولاء لتلك الشخصيات. ويدلل شيشرون على وجهة نظره هذه بشذرة يمتدح فيها إنيوس القائد كورنيليوس كيثيجوس Cornelius Cethegus

"Additur orator Cornelius suaviloquenti ore, Cethegus Marcus,Tuditano ${ }^{59}$ college, Marci filius ......... Is dictust ollis popularibus olim qui tum vivebant homines atque aevum agitabant,

Flos delibatus populi

$$
\begin{aligned}
& \text { Suadaeque }^{60} \text { medulla."61 } \\
& \text { " ارتبط ماركوس كورنيليوس كيثيجوس ،الخطيب ذو الحديث الساحر، } \\
& \text { بعلاقة زمالة مع توديتانوس، }
\end{aligned}
$$

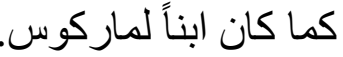

$$
\begin{aligned}
& \text { ال....... وهو كان يدعى في يوم من الأيام من قبل هؤ لاء المو اطنين } \\
& \text { الذين كانو ا في هذا الحين أحياءً ويمارسون حياتهم } \\
& \text { بز هرة الثعب المنتقاة. }
\end{aligned}
$$

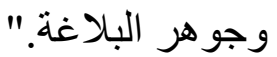


التطورات السياسية وانعكاساتها على أثعار إنيوس الدرامية والملحمية

حيث يرى شيثرون في مديح إنيوس للقائد كيثنيجوس عملاً وطنياً هاماً، لأنه

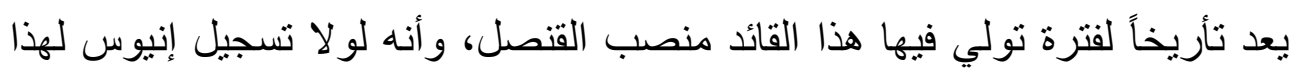

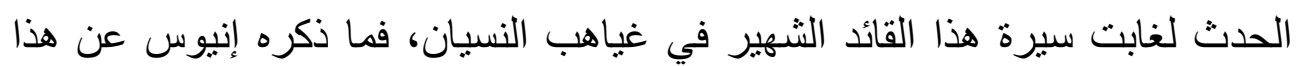
القائد كان صدقاً وحقاً. يقول شيشرون في سياق دفاعه عن إنيوس:

"nulla suspicio est amicitiae causa esse mentitum.

" ليس هناك سبب يدعوني إلى الثنك في أن [إنيوس] كانت تدفعه صداقته

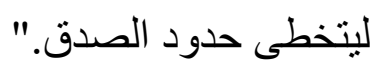

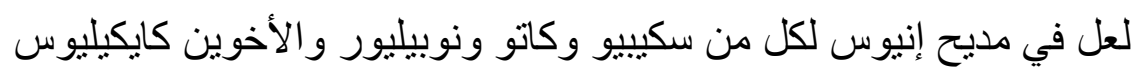
و غيرهم ما يجعل من الصعب ادعاء و لاء إنيوس لإحدى تلاك الثخصيات؛ فالعلاقة

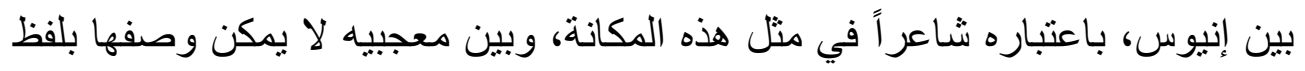

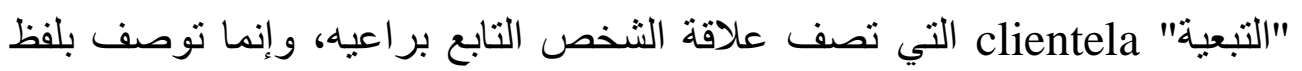
amicitia

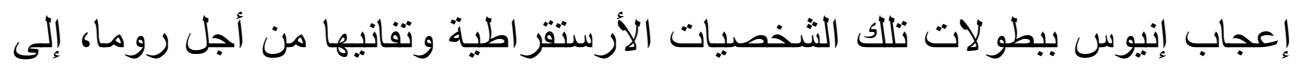

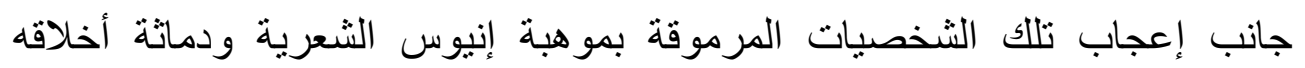

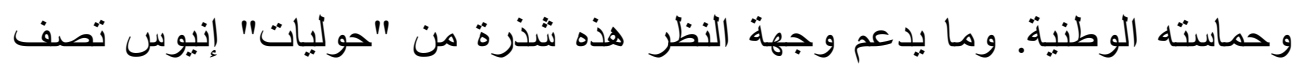

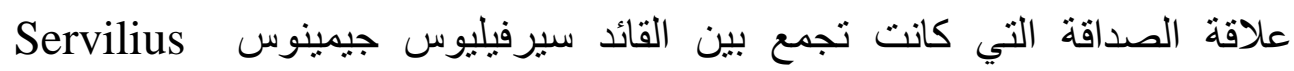
Geminus

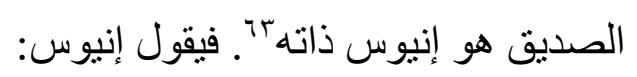

"Haece locutus vocat quocum bene saepe libenter mensam sermonesque suos rerumque suarum comiter inpertit, magnam cum lassus diei partem trivisset de summis rebus regendis, consilio indu foro lato sanctoque senatu; 


\section{فاتن عثمان}

quoi res audacter magnas parvasque iocumque

eloqueretur sed cura ------------------

ingenium quoi nulla malum sententia suadet

ut faceret facinus levis aut malus ; doctus fidelis

suavis homo facundus, suo contentus, beatus,

scitus, secunda loquens in tempore, commodus,

verbum paucum."

" هذا الوصف يتحدث فيه عن شخص بشاركه دائماً - بألفة وبحب وبابتهاج-

مائدته، و أحاديثه، وشئونه

ويحاول التخفيف عنه عندما يقضي معظم يومه منهكاً في تسبير الأمور

العظيمة عن طريق تقديم المشورة في سوق[روما] الكبير

والسناتوس المقدس. إنسان أثناء رفقته

يتحدث [القائد] بجر أة في الأمور العظيمة و الصغيرة

بل ويتفكه بابتهاج .

إنسان لا تأمره نفسه بأي سوء

ولا يفعل الصغائر فضلاً عن الكبائر. مثقف موثوق به

إنسان ظريف، لبق، قانع بما لديه، سعيد

حاذق. إنسان يتحدث في الوقت المناسب، مؤدب، مقتصد في حديثهـ. ."

لقد أرسى إنيوس من خلال هذا الوصف معايير شخصيته التي تجمع بين القوة والعقل، مبلوراً دوره الاجتماعي باعتباره صديقاً لديه من الخصال ما يجعله يستحق ثقة كبار رجال الدولة"1. فربما تكون تلك الصفات هي التي جذبت سكيبيو الأفريقي إلى إنيوس فصادقه، وربما تكون هي التي لفتت انتباه كاتو الرقيب إليه في 


\section{التطورات السياسية وانعكاساتها على أثعار إنيوس الدرامية والملحمية}

جزيرة سردينيا، ومن ثم اصطحبه معه إلى روما. وكانت تلك الصفات أيضاً محط إعجاب وتقدير نوبيليور فاصطحبه معه في حملته على أيتوليا. ولعل هذا الوصف الذي ساقه إنيوس عن نفسه كان دفاعاً ورداً و افيين على انتقاد كانو الرقيب لنوبيليور على اصطحابه لإنبوس معه في حملته على إقليم أيتوليا، واعتبار هذا الأمر نوعاً من الدعاية لبرنامج هذا القائد السياسي. كما يعزز هذا الوصف فكرة أن إنيوس وغيره من الثعر اء الذين امتدحوا كبار رجال الدولة، لم يكونوا صعاليكاً أو متطفلين على مآدب

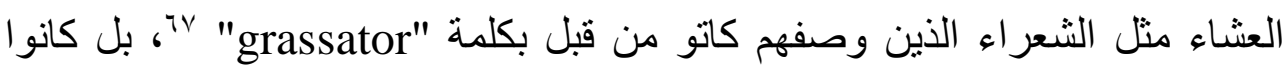
رجالاً يتمتعون بثقافة واسعة وفكر عميق ونزاهة أخلاقية. فربما قصد كاتو شعراء الأغنية القديمة التي كانت تُشند حول المآدب على "مر أجيال عديدة سابقة على عصره

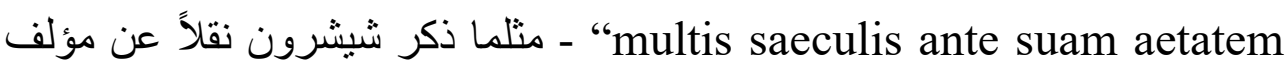
كاتو "الأصول"^^" و التي توارت مع مرور الزمن لتحل محلها الأغاني التاريخية التي سجلت للأجيال التالية أهم إنجازات أجدادها، ونقلت إليها أهم الأحداث و المآثر التي شكلت التاريخ الروماني، وربما مثلت أشعار إنيوس جزءاً من هذه الأغاني في ذلك الوقت. فقد ظهرت في القرن الثاني ق.م. مجموعة جديدة من الثعر اء المستقلين مادياً ممن استطاعو ا إحر از مكانة أدبية مرموقة أو ممن كانو ا ينتمون إلى طبقات اجتماعية بارزة،79، أخذ البعض منهم يمنحون رعاتهم المجد والخلود من خلال أثعار هم مقابل حصولهم على الدعم والتشجيع والثهرة، بخلاف أسلافهم من الشعر اء الذين كانوا يهدفون من نظم الأشعار إلى تحقيق المكاسب المادية فقط.

من خلال هذا العرض السابق يمكن القول إنه على الرغم من ارتباط نشأة الأدب اللاتيني بالحياة السياسية في روما حين كانت في مسيس الحاجة إلى وسيلة تروج بها لمشروعاتها التوسعية وتخدم بها مصالحها الوطنية، وعلى الرغم من الثوا هد التي تشير إلى تسييس رواد الثُعر اللاتيني لأشعارهم، إلا أنه لا يجب أن أن 


\section{فاتن عثمان}

ننظر إلى أشعار إنيوس باعتبار ها مقطوعات شعرية مدفوعة الأجر، ومن الجور

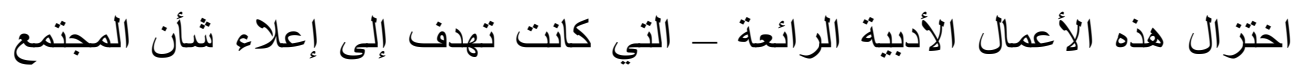

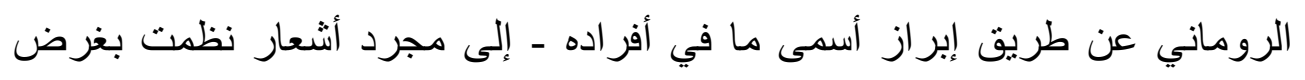
تحقيق أمجاد شخصية، لذلك فمن الأفضل أن نقيم أغاني إنيوس باعتبار ها أشعار آ

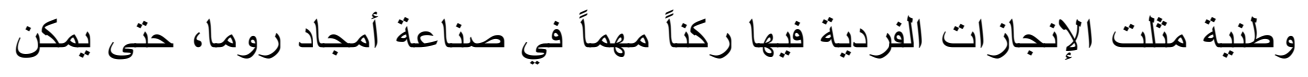
تذوق ما بها من خصائص فنية مميزة تنم عن شاعرٍ موهوب، وليس شاعر آ مأجوراً.

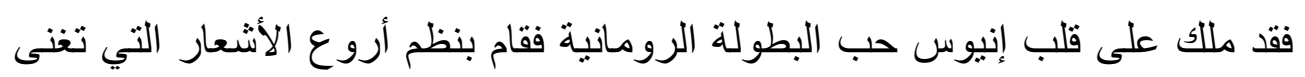
فيها بإنجاز ات من كانوا يقودون روما في حروبها مثل سكيبيو الأفريقي الذي كان أعظم قائد عسكري في عصر إنيوس، حيث كان الحظ حليفه، والنصر يسير في ركابه، لذلك أبت ملكة إنيوس الشعرية إلا أن تتجذب نحوه، فنظم له الأشعار التي تتغنى بمآثره.

وربما لم يثر برنامج نوبيليور السياسي قريحة إنيوس الشعرية، وأنما أثنار ها برنامج هذا القائد الثقافي ورقيه الفكري وحماسته الثديدة للأفكار الإغريقية. فقد أعاد نوبيليور بناء معبد الإله هيركوليس - النظير الروماني للإله هير اكليس الإغريقي -

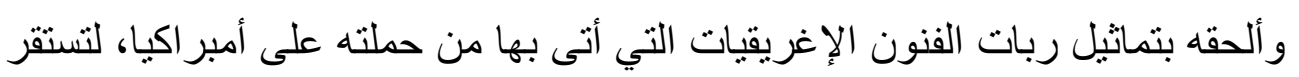

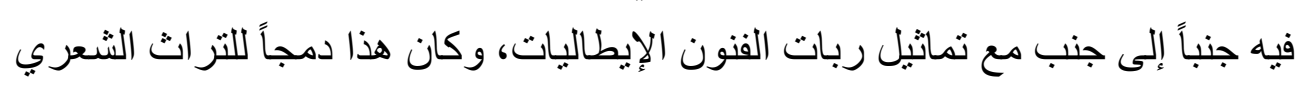
الإغريقي و الروماني معاً، و الذي يعكس بوضوح ما تناوله إنبوس ببر اعة في معظم أشعاره.

وربما كان إعجاب إنيوس الصادق بالقوة الأخلاقية لبعض المحاربين هو ما

دفعه إلى إضافة الكتاب السادس عشر إلى "حولياته" ليتغنى فيه بشجاعة التربيونين كايكيليوس، ويثبت أنه لم يعكف في أشعاره على امتداح كبار رجال الدولة من الطبقة الأرستقراطية فحسب، بل احتفى أيضاً برجال كانوا أقل مكانة لكنهم كانوا أكثر شجاعة، وبذلك لا تترك أثعاره إنطباعاً بتحزبه في المديح أو بوجود صراع طبقي اجتماعي وسياسي في روما. 


\section{التطورات السياسية وانعكاساتها على أثُعار إنيوس الارامية والملحمية}

لذا لم تشكل أشعار إنيوس أية دوافع سياسية أو حتى اعتبار ات مادية. ذلك ألك أن عبقرية هذا الشاعر قد كفلت له منزلة اجتماعية رفيعة بين الأوساط الرومانية الراقية، ومصدر رزق مستقل. فربما كان كلّ من كاتو وسكيبيو الأفريقي ونوبيليور دعاة لنظرية تقول إن الثعر ليس للتسلية والإمتاع فحسب، بل كان يخدم أيضاً القضايا الوطنية العامة، وربما كان إنيوس أول شاعر روماني يتناول قضايا هؤلاء الرجال في أشعاره، ليس بدافع الصداقة أو الولاء لهذه الثخصيات، وأنما عن قناعته الثخصيبة

$$
\text { بإخلاصها وتفانيها في حب روما. }
$$

\section{الهوامش:}

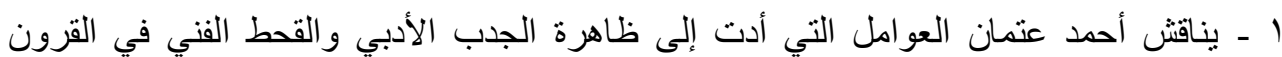

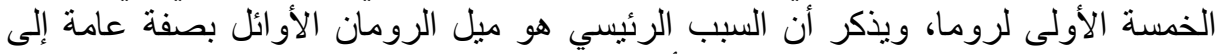

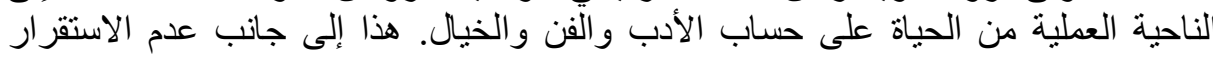

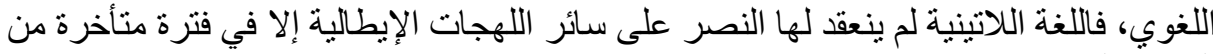

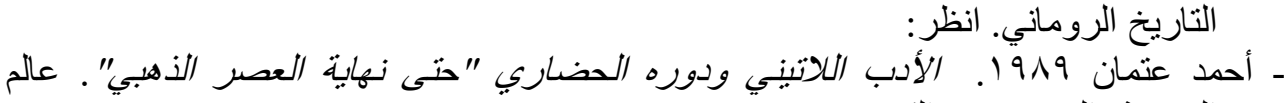

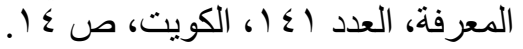

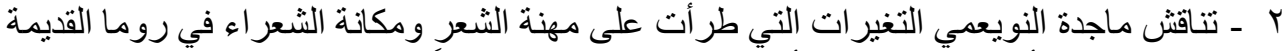

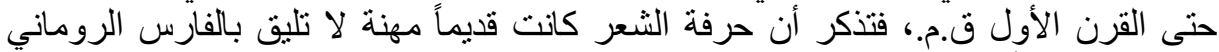

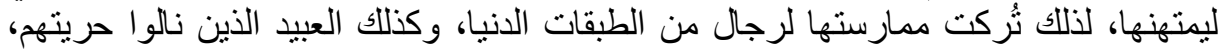

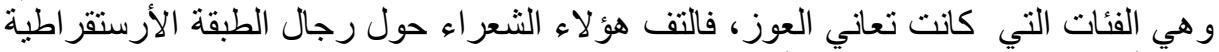

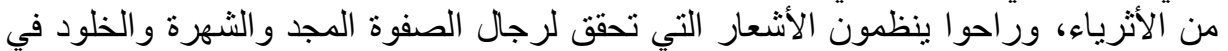

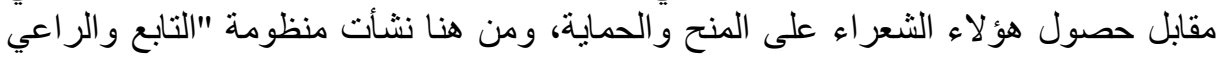
الروماني" Roman Client-patron، هولاء الثعلى حد تعبير الناقدة.

- M. El-Nowieemy 2013. "Hellenism, Alexandrianism, and Roman Enlightenment." Proceedings of the International Conference on Alexander, the Greek Cosmos-System and Contemporary Global Society. Thessaloniki, Greece. 408-209, esp. 408. Accessed at 17/2/ 2015. 
3 Sextus Pompeius Festus - بمدنا عالم اللغة الروماني سكستوس بومبيوس فيستوس بـون

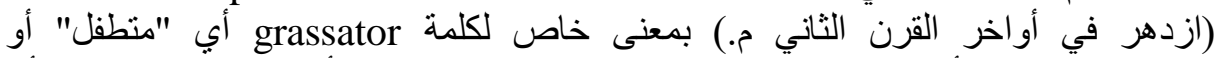

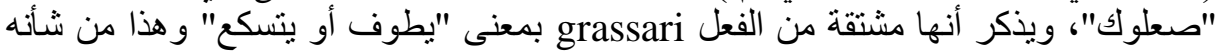

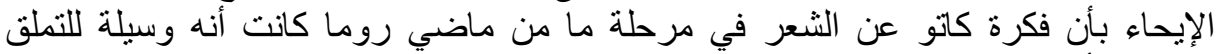

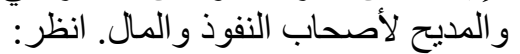

.De Sig. Ver., "Grassari”" 12-14 Fest., -

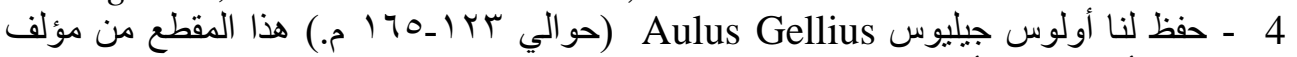

- Gell., Noct. Att., 11, 2, 5.

$$
\text { كاتو "أغنية عن الأخلاق": النائ }
$$

5 - يشير شيشرون هنا إلى مؤلف كاتو "الأصول" Origines ليناقش بعض الحقائق التي تتصل

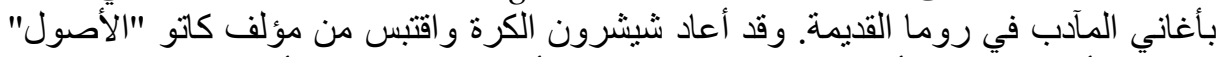

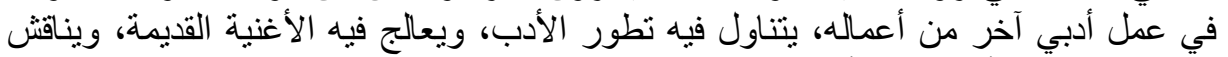

.Cic., Brut., 71-76 طبيعة الكتابات الأولى في الأدب اللاتيني. انظر :

- Cic., Tusc. Disp., 1, 3.6

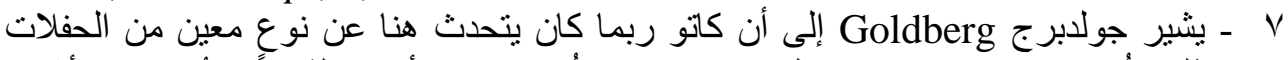

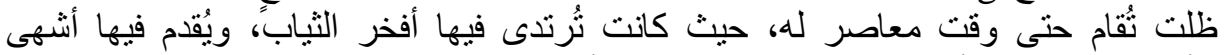

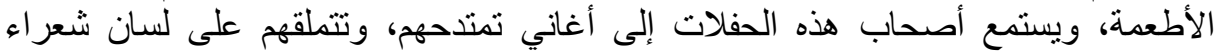

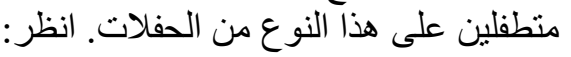

- S. M. Goldberg 2005. "The Early Republic: The Beginnings to 90 BC." in A Companion to Latin Literature. Oxford, 15-30, esp. 24.

- Cic., Brut., 72-73. ^

$$
9 \text { - عن مجيء العبيد إلى روماودور هم الفعال في الحياة الفكرية والاجتماعية، انظر: }
$$

T. J. Cornell 1995. The Beginnings of Rome: Italy and Rome from the Bronze Age to the Punic Wars (c. 1000-264 BC). London, New York,

T. N. Habinek 1998. The Politics of Latin Literature: Writing, Identity, . and Empire in Ancient Rome. Princeton, Princeton University Press, 35 - E. Sciarrino 2006. "The Introduction of Epic in Rome: Cultural Thefts and .Social Contests." Arethusa 39: 449-469, esp. 451 • ا ـ لدر اسة طبيعة العلاقة بين الشعر اء ور عاة الأدب في الفترة المبكرة من تاريخ الأدب اللاتيني،

O. Taplin, Literature in the Roman World. Oxford, 10 انظر : النا 11

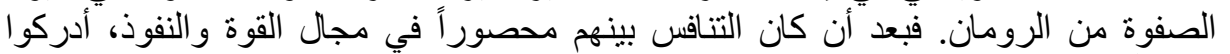

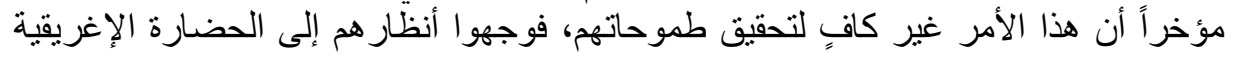


التظورات السياسية وانعكاساتها على أشعار إنيوس الدرامية والملحمية

وشغفو ا بسحر ها، وحرص كل منهم على تعلم اللغة الإغريقية حتى أصبح إتقانها إحدى السمات

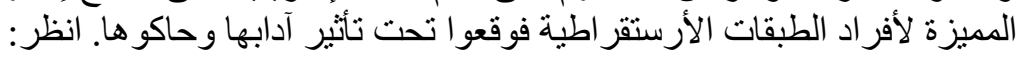

- M. El-Nowieemy 2011. "Intellectual and Military Might: The Politics of Learning between Alexandria and Rome." Alexandria and other

Centers of Thought in Ancient Egypt. ed. by M. Abdel Nasser and S.

Hamouda. Alexandria, 69-84, esp. 74.

r ا ـ كان تفويض رجال الصفوة والقادة الرومان للشعر اء بترجمة المسرحيات الإغريقية وعرضها

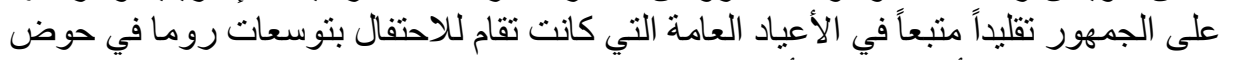

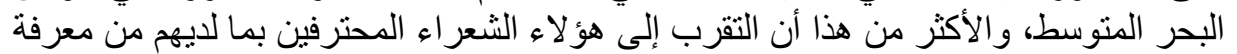

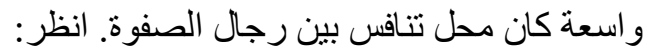

E. Sciarrino 2004. "Putting Cato the Censor's Origines in Its Place." .ClAnt 23: 323-357, esp. 327

- Cic., Brut., 72. 11

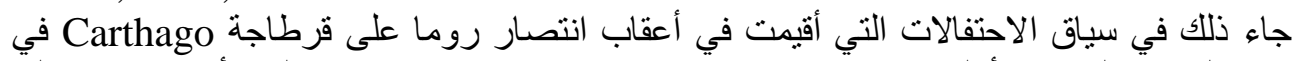

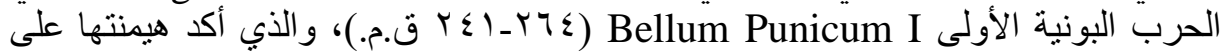
جنوب إيطليا وصقلية. عن ظروف الأليف أندرونيكوس لعرضه المسر المسرحي، أنظر :

- E. S. Gruen 1990. Studies in Greek Culture and Roman Policy. Leiden, 8284.

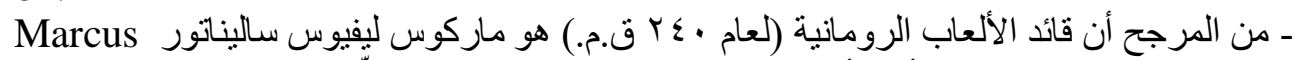
decemviri sacris Livius Salinator Paciundis consul

- S. M. Goldberg 1974. "Poetry, Politics, and Ennius." TAPhA 119: 247.261 , esp. 251

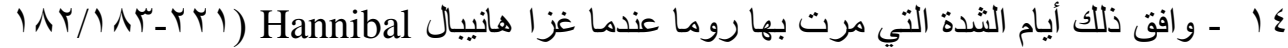

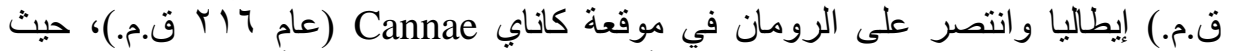

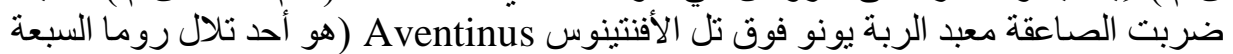

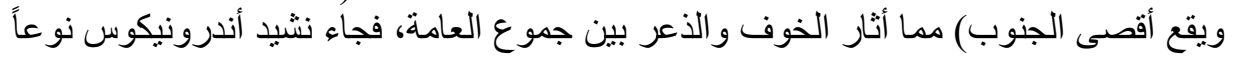

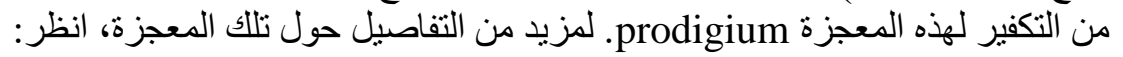

- Liv., A.U.C., 27, 36-37.

- Fest., De Sig. Ver., 15, 5, 23-29.10

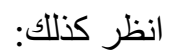

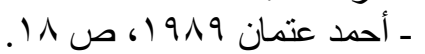
17 - عن هذه الر ابطة الأدبية الرسمية، ونظرة المجتمع الجديدة للثعر والثعر اء، انظر: .1976. "The Collegium Poetarum." BICS 23: 79-95 N. Horsfall - Suet., De Illus. Gram., 1.IV 
- Cic., Brut., 73-74.1^

وقد حصل أندرونيكوس على حريته من راعيه ماركوس ليفيوس ساليناتور مقابل تعليم أبنائه وتثقيفهم، وسُمي ليفيوس على اسمه. انظر:

. E. S. Gruen 1990, 84-85 -

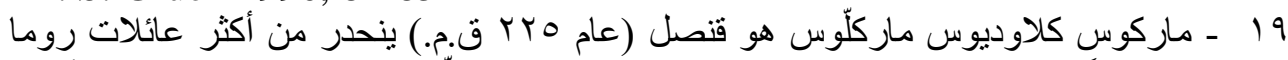

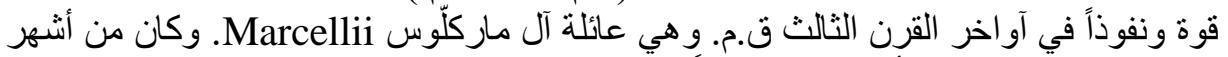

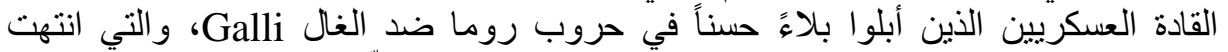

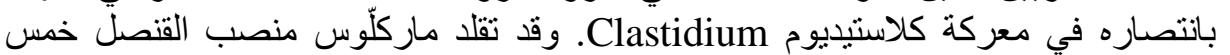

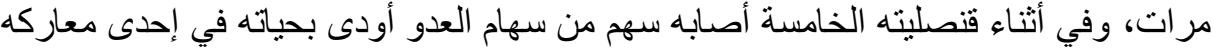

- Plut., Marc., 30.

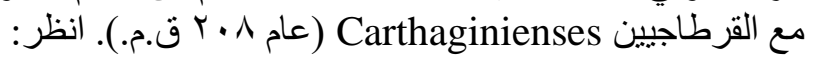

• . - سميت هذه المعركة بهذا الاسم نسبة إلى مدينة كلاستيديوم التي تقع في منطقة غاليا كيسالبينا Gallia Cisalpina - OCD 2012, s.v. "Clastidium".

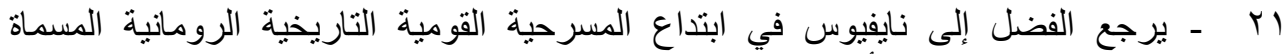

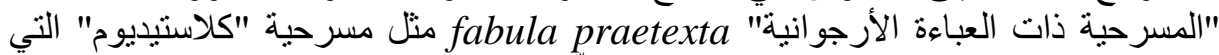

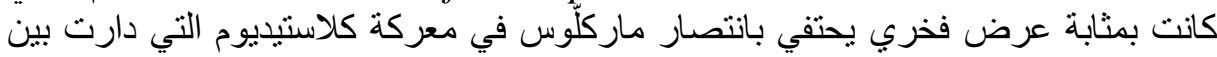

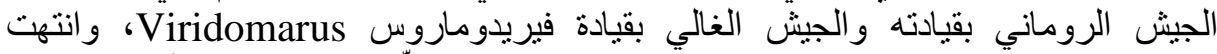

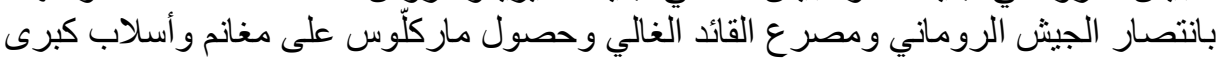
spolia opima H. I. Flower 2000. "The Tradition of the Spolia Opima: M. Claudius .Marcellus and Augustus." CLAnt 19: 34-64, esp. 37

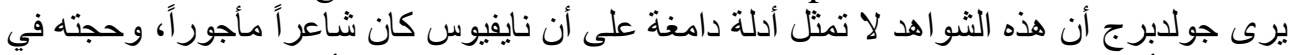

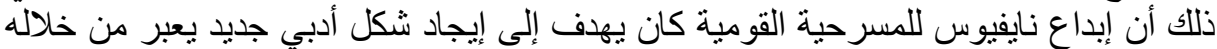

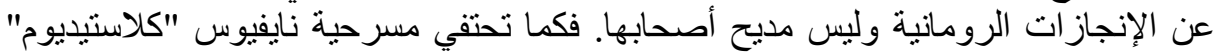

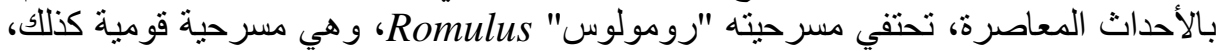

- S. M. Goldberg 1974, 247-261, esp. 251. بموضو ع أسطوري.

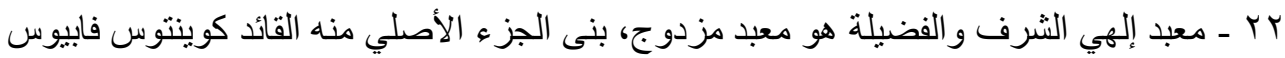

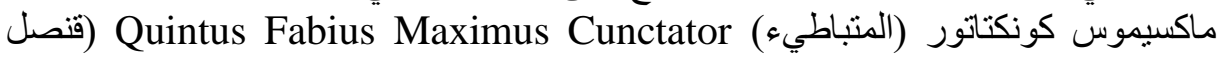

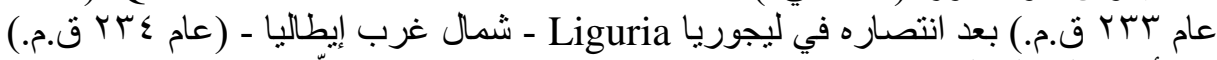
وقد أهداه إلى إله الثرف Honos

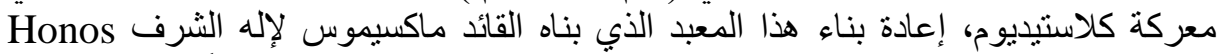

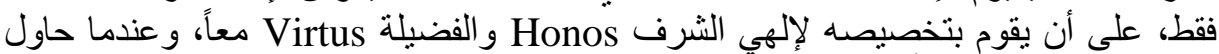

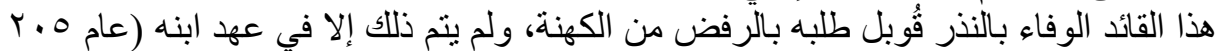
ق.م.). انظر: 
التطورات السياسية وانعكاساتها على أشعار إنيوس الارامية والملحمية

Cic., De Nat. Deor., 2, 61 -

انظر كذلك: - ان

. A Topographical Dictionary of Ancient Rome. 1949 S. B. Platner completed and rev. by Thomas Ashby. London, Oxford University

.Press, 258-260

rr T - جاء نفي نايفيوس نتيجة لنقده السياسي الصريح في إحدى مسرحياته الكوميدية، للفضائح

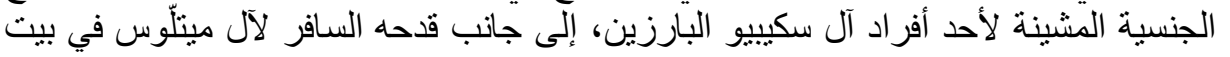

شهير قال فيه نايفيوس:

"Fato Metelli Romae fiunt consules." （Naev., Var., fr. 2.) " بالقدر يصير آل ميتلّوس قناصل في روما."

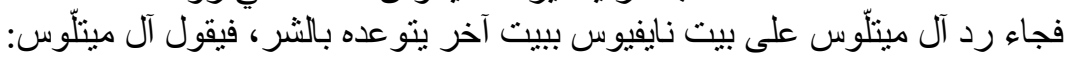

"Dabunt malum Metelli Naevio poetae." (Cic., Verr., 1, 29.)

" سوف يسوم آل ميتلوس الشاعر نايفيوس سوء العذاب."

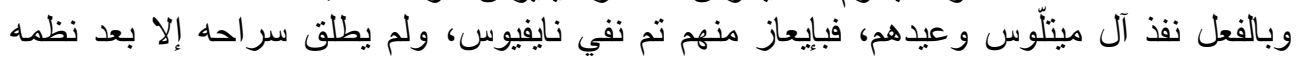

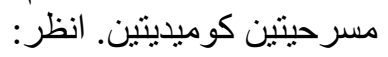

- A. J. Boyle 2006. Roman Tragedy. New York, 53-54.

- Cic., Pro Arch., 22.24

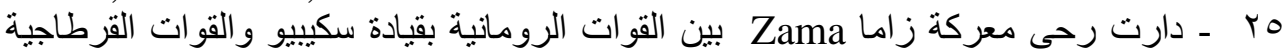

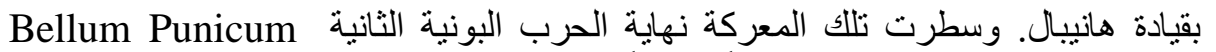

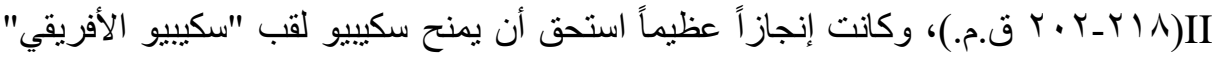

74. - A. Acimovic 2007. Scipio Africanus. New York,

Scipio Africanus

- Enn., Scip, frr. 10-11.26

Enn. Epig., frr. 5-6. ,27

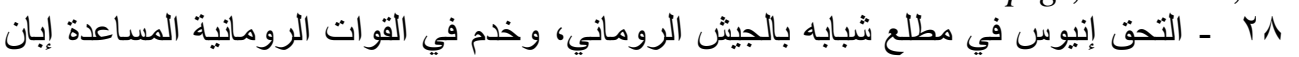

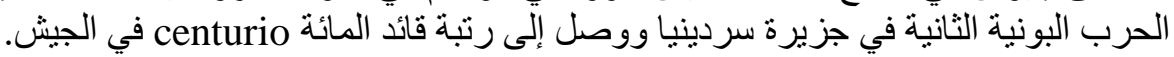

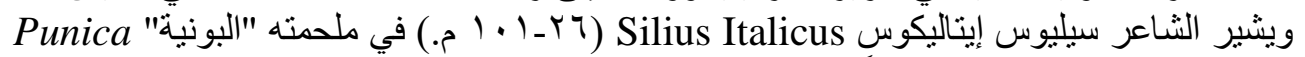

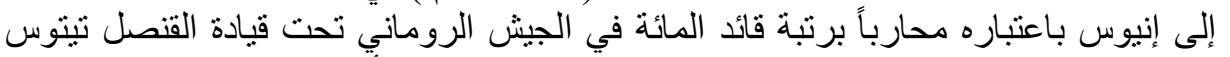

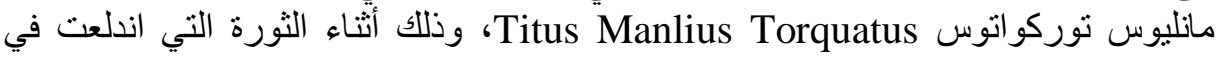

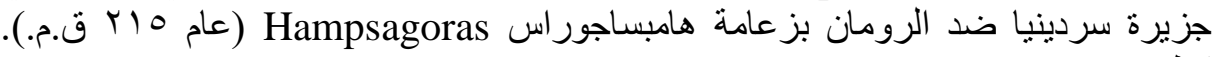

Sil. Ital., Pun., 12, 387-414 -

انظر : انيز

q T - يثير عبد المعطي شعر اوي في هذا الصدد إلى أن التأثير الإغريقي على الفكر الروماني ظهر

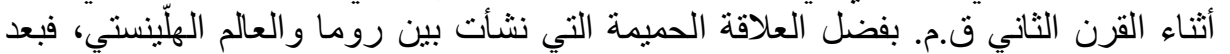

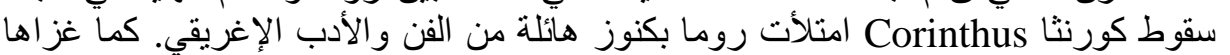

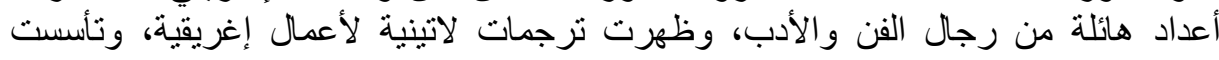




\section{فاتن عثمان}

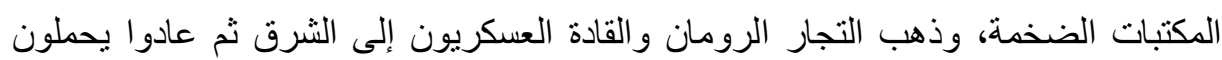

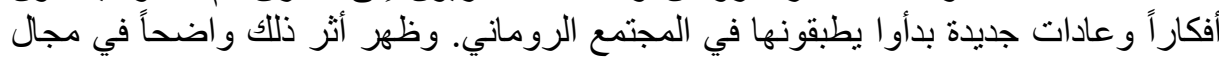

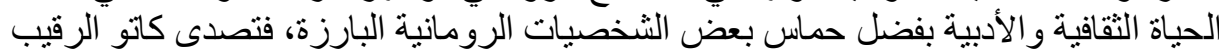

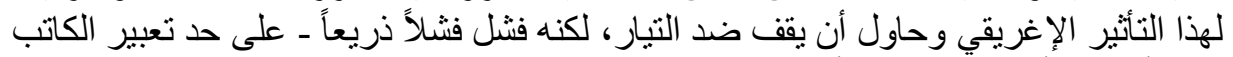

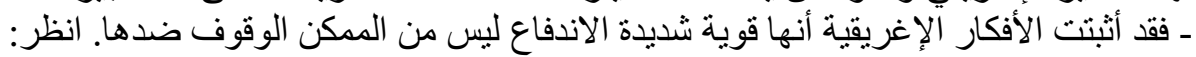

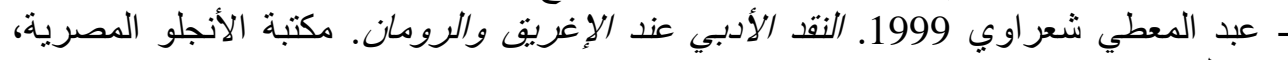

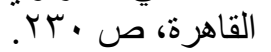

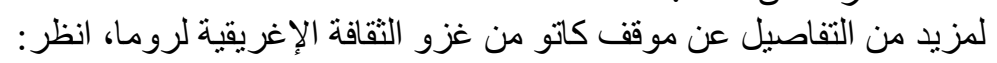

E.S. Gruen 1992. Culture and National Identity in Republican Rome. .London, 80-84

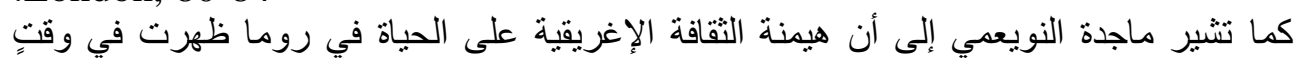

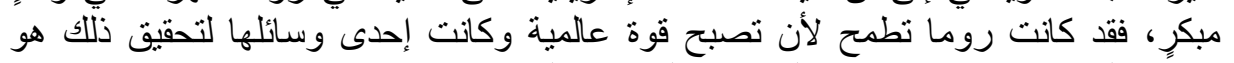

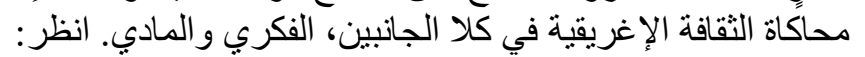

.M. El-Nowieemy 2013, 403-415, esp. 405 -

.Aurel Vic., De Vir. Illus., 47- r.

تشير فانثام Fantham إلى أن العلاقة التي جمعت بين إنيوس وكاتو الرقيب مثلت رابت رابطة بين قطبي

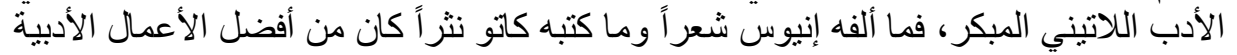

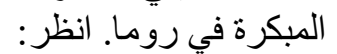

E. Fantham 1999. Roman Literary Culture: From Cicero to Apuleius. .Johns Hopkins University Press, 11

اس ـ ماركوس فولفيوس نوبيليور هو قائد روماني ينحدر من أكبر العائلات الأرستقر اطية في روما

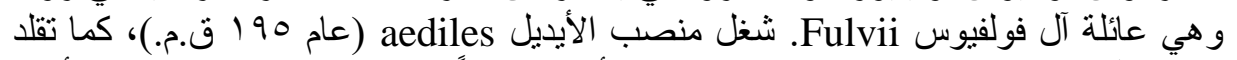

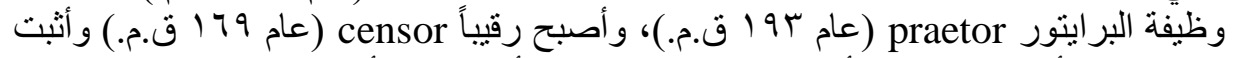

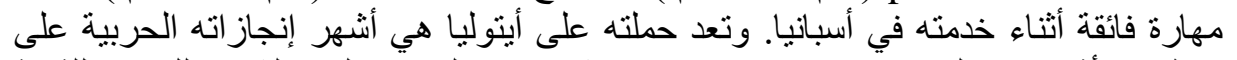

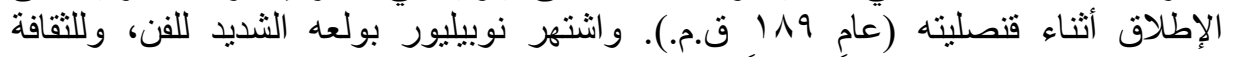

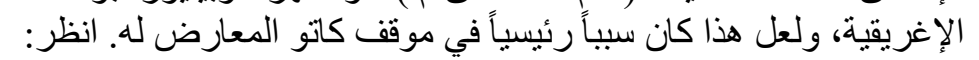
- Liv., A.U.C., 42, 32.

- OCD 2012, s.v. "Nobilior".

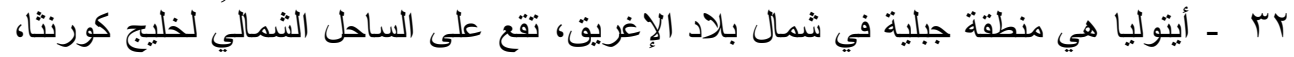

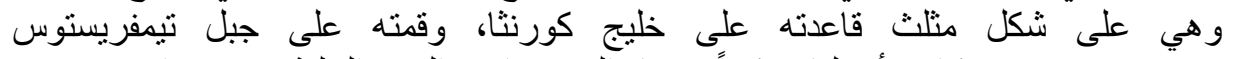
Tymphrestus

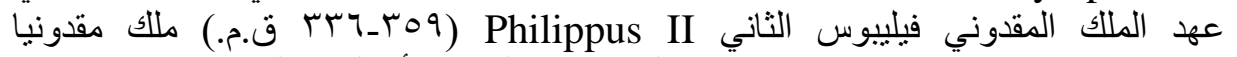
Macedonia

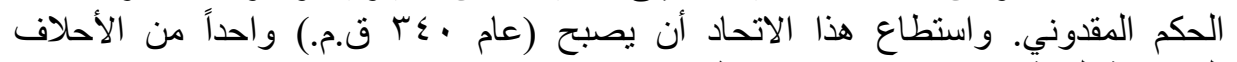
." OCD 2012, s.v. "Aetolia العسكرية المؤثرة في بلاد الإغريق. انظر : 


\section{التطورات السياسية وانعكاساتها على أثعار إنيوس الدرامية والملحمية}

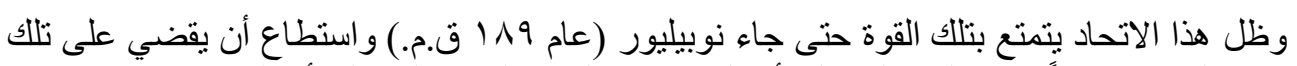

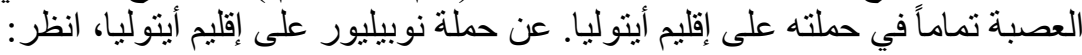

M. Beard 2007. The Roman Triumph. Harvard University Press, 264. rr - نظم إنيوس روايتين تاريخيتين رومانيتين إحداهما في التاريخ المعاصر له وهي وهي مسرحية

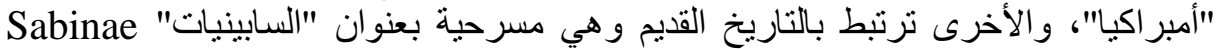

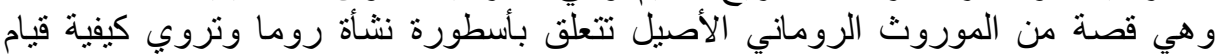

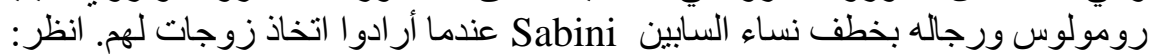

- H. J. Rose 1996. Handbook of Latin Literature: From the Earliest Times to the Death of ST. Augustine. London, 36.

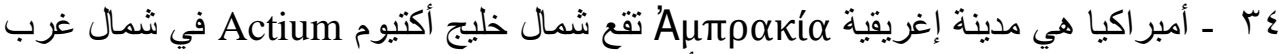

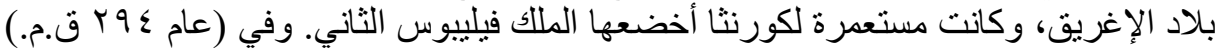

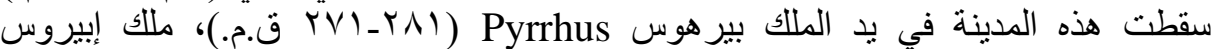
Epirus

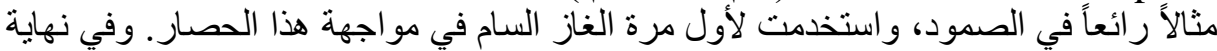

- Poly., Hist., 21, 27, 1-9.

- Liv., A.U.C., 38, 43.

- OCD 2012, s.v. “Ambracia”.

- Enn., Fab. Praet., Ambr., fr. 377-378.35

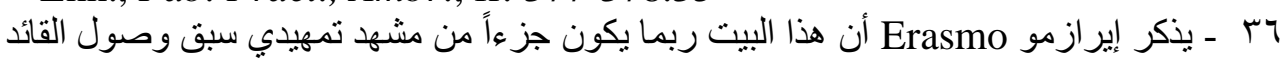

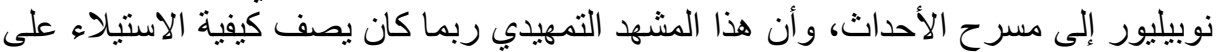

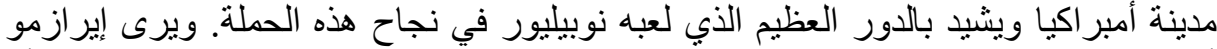

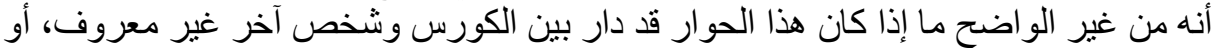
أنه قد دار بين شخصين الوافح دون إذان هذرس. انظر :

- M. Erasmo 2004. Roman Tragedy: Theatre to Theatricality. University of Texas Press, 72.

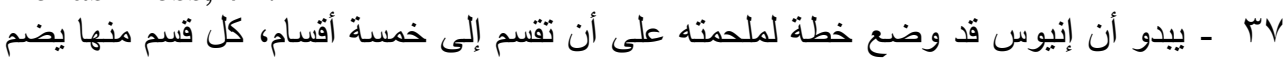

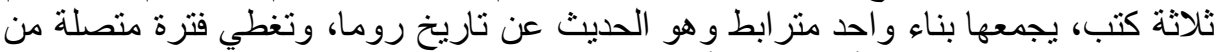

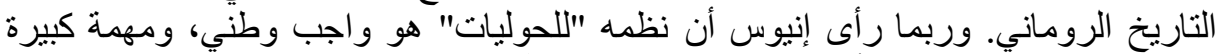

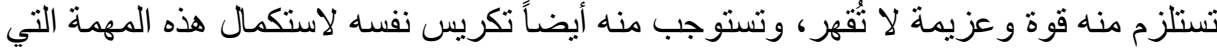

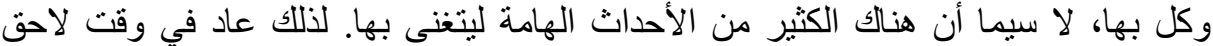

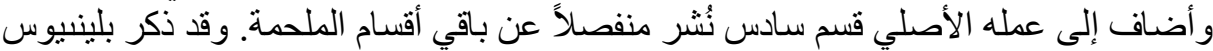

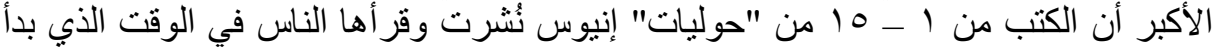

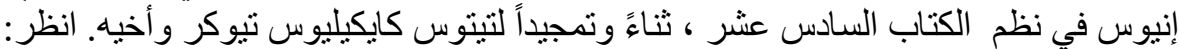

- Plin., Nat. Hist., 7, 101. 


\section{فاتن عثمان}

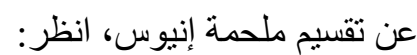

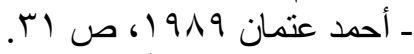 عن معالجة إنيوس لأقسام ملحمنه، انظر : أنسان} - P. Toohey 2007. Melancholy, Love, and Time: Boundaries of the Self in .Ancient Literature. University of Michigan Press, 202-203

- Enn., Ann., fr. 385-386.38

- Cic., Brut., 20, 79. Үq

•ـ ـمن الأسباب التي ساهمت في إثارة غضب كاتو الرقيب حيال مر افقة إنيوس للقائد نوبيليور

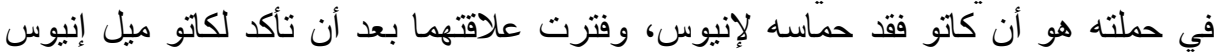

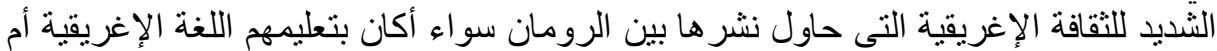

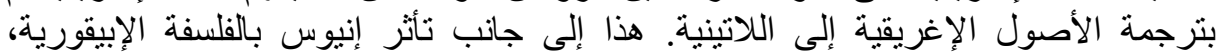

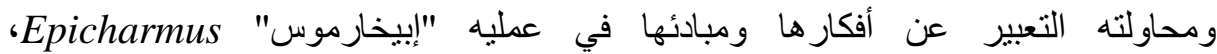

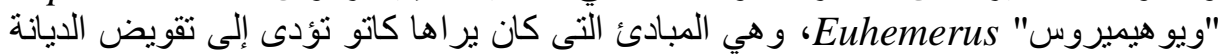

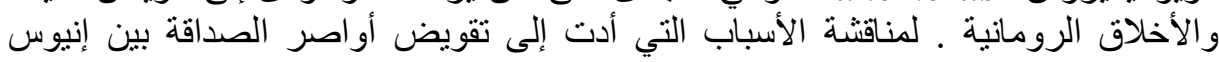

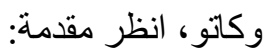
ed. and trans. by E.H. . Ennius and Caecilius, Remains of Old Latin, Vol. 1 .Warmington, London, 1988, XXi

اء - تناقش الناقدة سكيارينو Sciarrino تصريح كاتو الرقيب في هذه الخطبة برفض تدخل

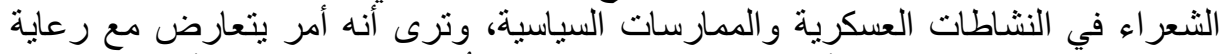

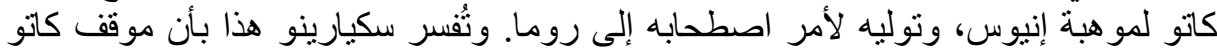

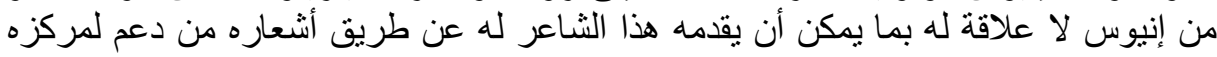

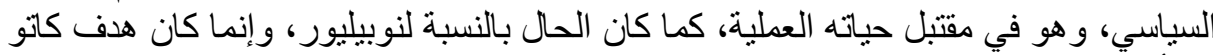

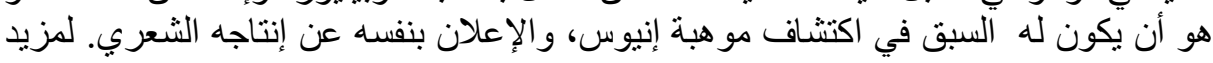

E. Sciarrino 2006, 449-469, esp. 465-

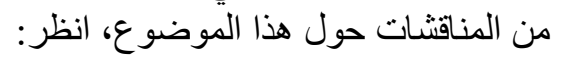

- Cic., Tusc. Disp., 1, 3.42

$$
\text { بـ - تبنى أستين Astin هذا الر أي. انظر : }
$$

- A. E. Astin 1978. Cato the Censor. Oxford, 110.

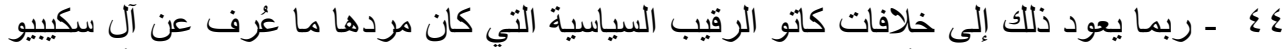

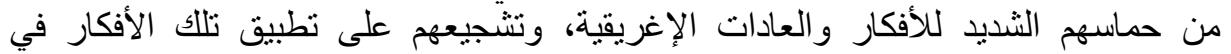

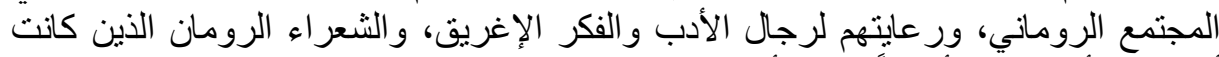

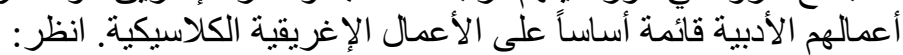

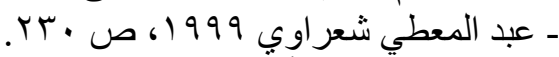

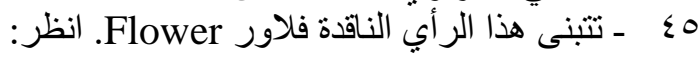
- H. Flower 1995. “Fabulae Praetextae in Context: When Were Plays on Contemporary Subjects Performed in Republican Rome?" CQ 45: 170190, esp. 184-186. 
التطورات السياسية وانعكاساتها على أشعار إنيوس الدرامية والملحمية

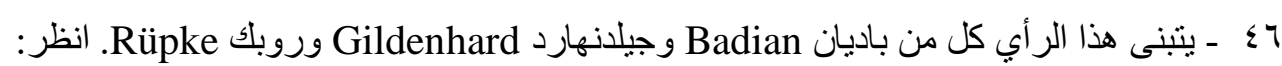
- E. Badian 1972. "Ennius and His Friends." in Ennius. ed. by Otto Skutsch. Geneve, 149-208, esp. 183.

- I. Gildenhard. 2003 "The 'Annalist' Before the Annalists: Ennius and his Annales." in Formen römischer Geschichtsschreibung von den Anfängen bis Livius: Gattungen, Autoren, Kontexte. ed. by U. Eigler, U.

Gotter, N. Luraghi and U. Walter. Darmstadt, 93 - 114, esp. 97.

- J. Rüpke 2006. 'Ennius' Fasti in Fulvius' Temple: Greek Rationality and Roman.” Arethusa 39: 489-512, esp. 489.

SV

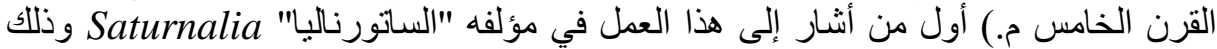

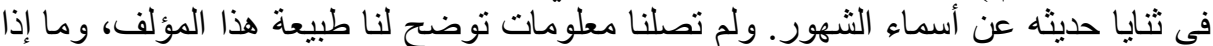

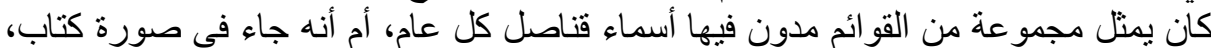

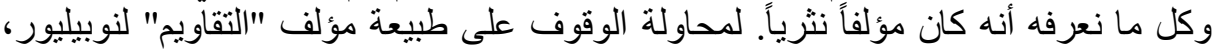

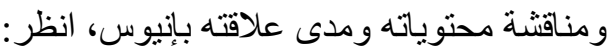

.J. Rüpke 2006, 489-512, esp. 491-511 -

1ـ - يقع سهل الإله مارس على حدود روما الشمالية الغربية، ويطوقه وادي نهر التيبر من جهة

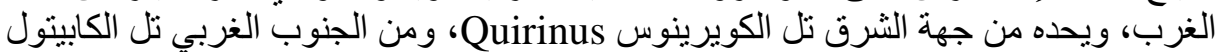
Capitolinus

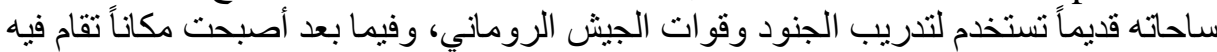

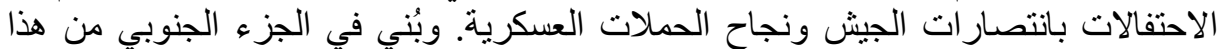

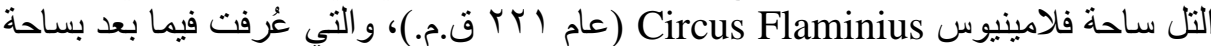

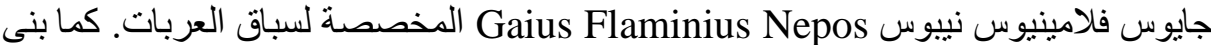

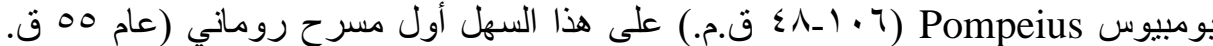

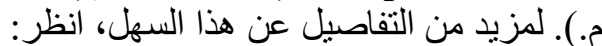

- L. Richardson 1992. A New Topographical Dictionary of Ancient Rome. Baltimore, Johns Hopkins University Press, 65-67.

9ء ـ هيركوليس Hercules هو المقابل الروماني للبطل الإغريقي المؤله هير اكلبس Heracles

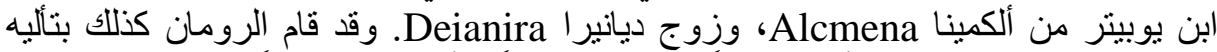

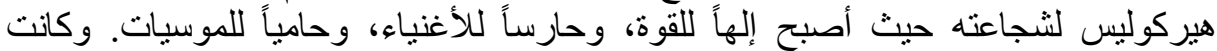

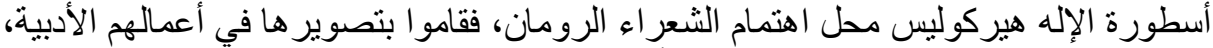

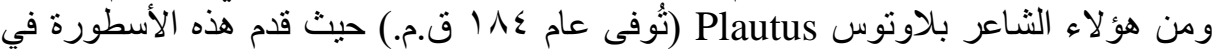

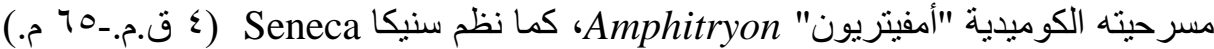

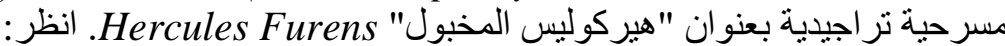

- OCD 2012, s.v. "Hercules".

- Mac., Sat., 1, 12, 16. ${ }^{\circ}$. 
- Plin., Nat. Hist., 7, 101.01

ـ لم يصلنا شيئ عن الأخوين كايكيليوس Caecilii سوى أنهما ترييونان عسكريان في الجيش الجيش

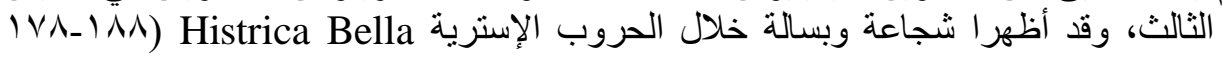

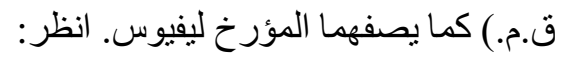

- Liv., A.U.C., 41, 1, 7.

- Enn., Ann., 16, fr. 409, 413-416.52

- E. Badian 1972, 149-208, esp. 185-187.

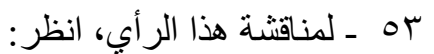

- S. M. Goldberg 1974, 247-261, esp. 258.

عه - يتبنى هذا الرأي روبك وباديان. ويقدم الأول دليلين يدعمان نظريته في تحزب إنيوس عند

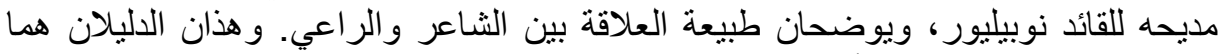
خطبة كاتو الرقيب التي أوردها شيشرون (Cic., Tusc. Disp., 1, 3.

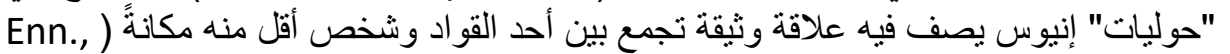
: Ann., VII, fr. 210-227.

- E. Badian 1972, 149-208, esp. 183.

- J. Rüpke 2006, 489-512, esp. 489.

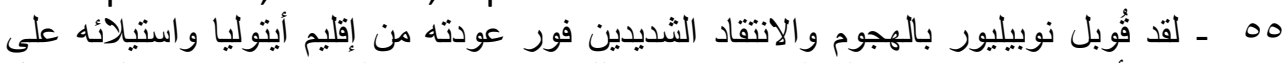

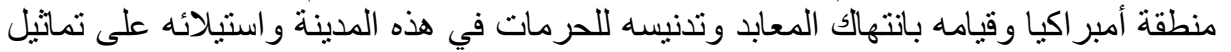
ربات الفنون الإغريقيات وغير ها من التماثيل و الغنائم الثمينة التي زين رين بالجزء التهاء الأكبر منها

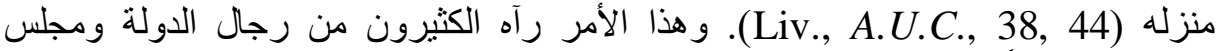

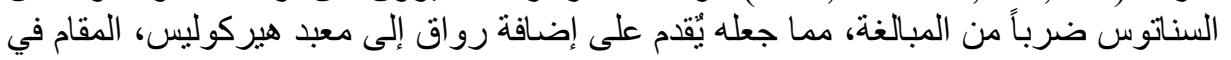

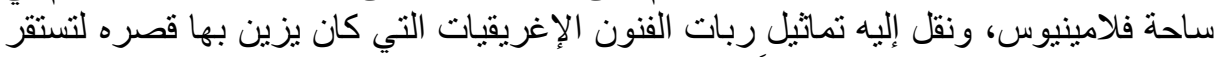

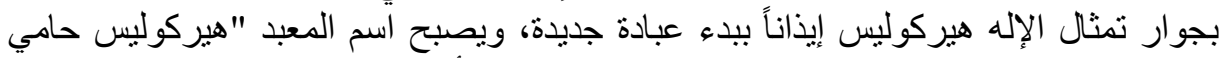

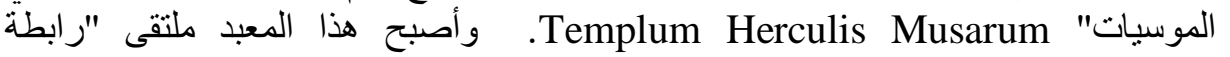
الثعر اء" Collegium Poetarum التي كانت تجتمع من قبل في معبد الربة مينرفا. انظر : . Plin., Nat. Hist., 34, 19 -

. Val. Max., Fac. et Dic. Mem., 3, 7, 11 -

- O. Skutsch 1944. “Enniana 1.” CQ, 38: 79-86, esp. 79. 10 - n - يتبنى هذا الرأي:

- S. M. Goldberg 1995. Epic in Republican Rome. Oxford, 132.

or

- E. Sciarrino 2006, 449-469, esp. 462.

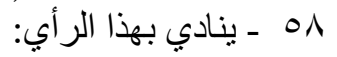

59 - توديتانوس هو بوبليوس سيمبرونيوس توديتانوس

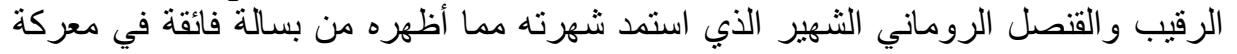

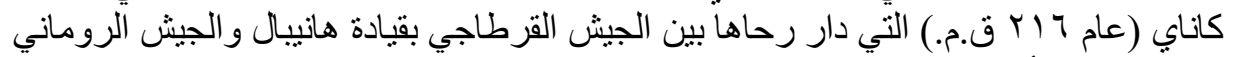
بقيادة القنصل أيميليوس باولَوس Aemilius Paullus وترنتيوس فاهار فارو 
التطورات السياسية وانعكاساتها على أثعار إنيوس الدرامية والملحمية

حيث لقى أيميليوس باولوس حتفه في المعركة بعد أن طوق هانيبال الجيش الروماني وتنغلب

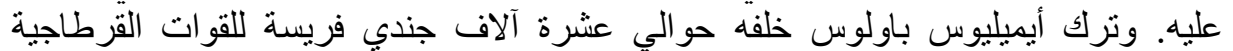

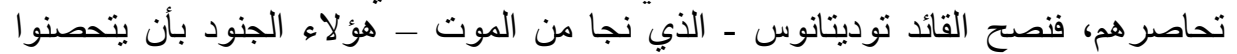

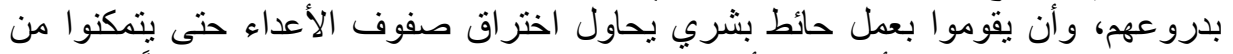

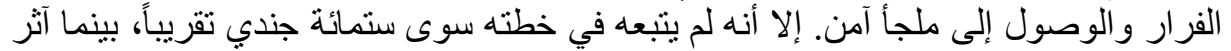

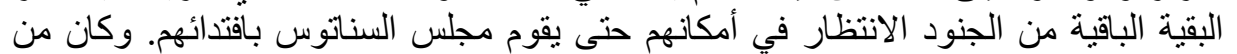

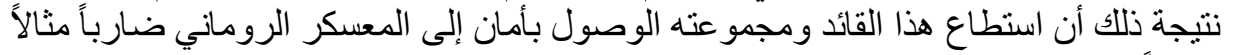

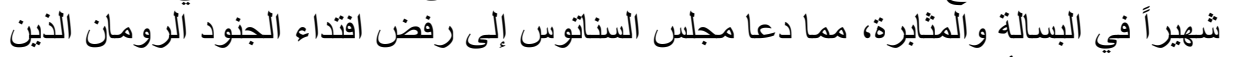

. Liv., A.U.C., 22, 6-12 ; 22, 60, 8-18 -

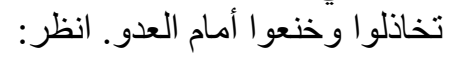

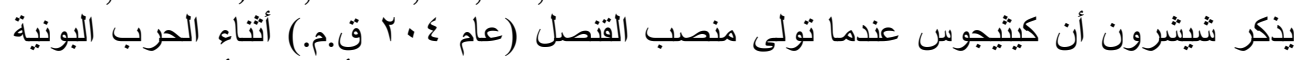

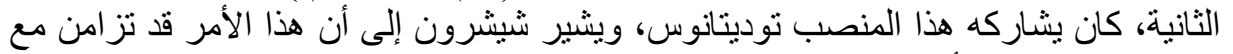

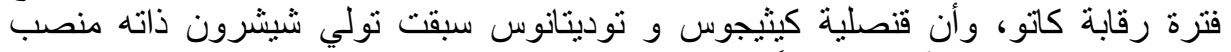
القنصل بحو الي مائة و أربعين عاماً. انظر :

. Cic., Brut., 15, 60 -

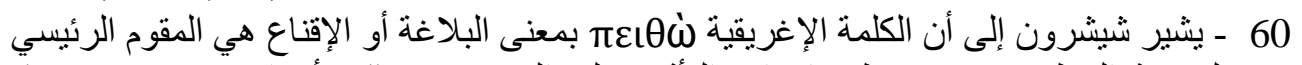

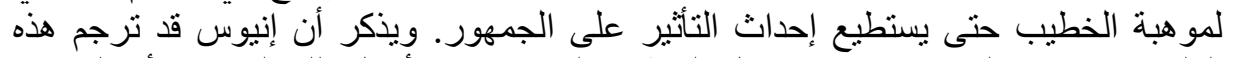
الكلمة الإغريقية إلى Suadae وجعلى الخطيب الخطيب الروماني هو أصل تللك الفصاحة أو البلاغة.

. - Cic., Brut., 15, 59

- Enn., Ann., IX, frr. 300 - 305.61

- Cic., Brut., 15, 58-59.7T

rا7 - هناك شهادة واضحة موثوق بها من أيليوس ستيلو Aelius Stilo (

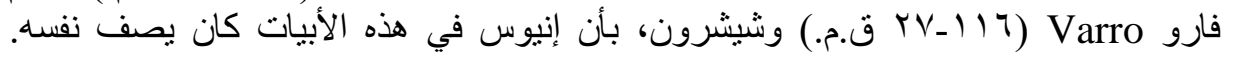

- Gell., Noct. Att., 12, 4, 4.

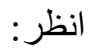

- Enn., Ann., VII, fr. 210-216, 219-22.64

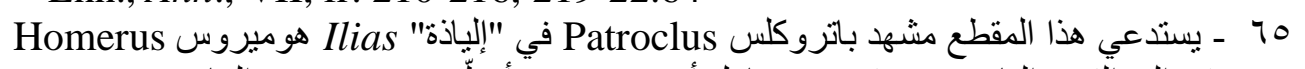

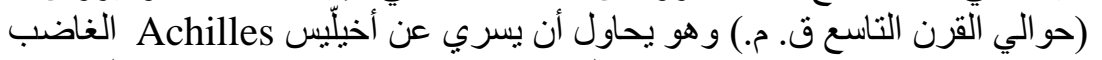

Vergilius فيليوس (Hom., Il., 9, 189-191.) (الصديق المخلص و المقرب إلى آينياس،

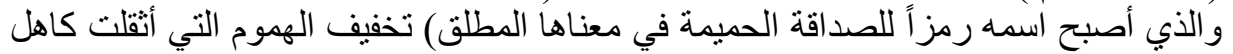

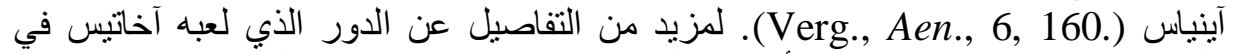

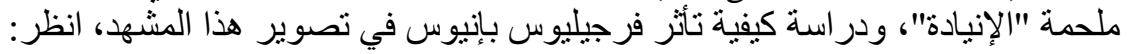

M. O. Lee 1979. Fathers and Sons in Virgil's Aeneid: Tum Genitor -

.Natum. New York, $106 \mathrm{f}$ 


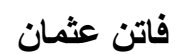

דا - يشبه جوسيلين Jocelyn مصاحبة إنبوس لرجل الدولة الروماني جيمينوس بمشاركة العلماء

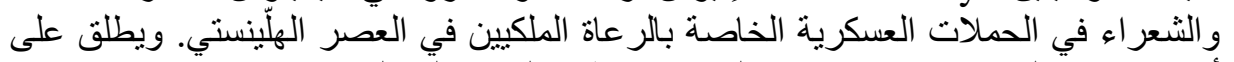

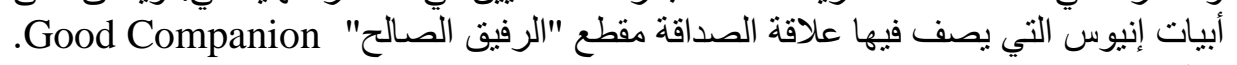
انظر :

- H. D. Jocelyn 1972. “The Poems of Quintus Ennius.” ANRW 1:987-1026, esp. 993-994.

$$
\text { عن تأثر إنيوس بأدب العصر الهُلّنستي في تصوير هذه الأبيات، انظر : }
$$

: 89-100, esp. 950V O. Skutsch 1963. "Enniana V." CQ -

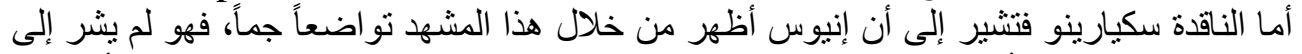

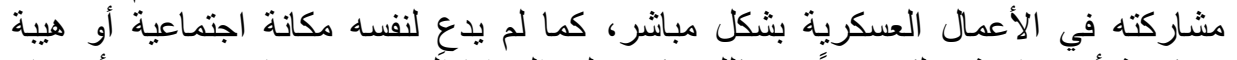

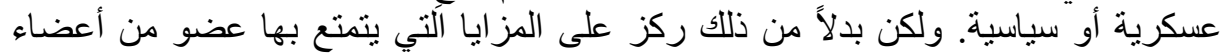

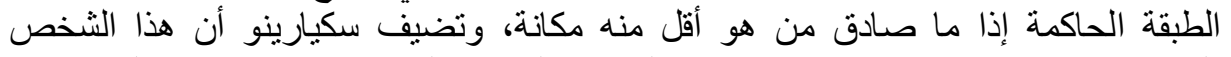

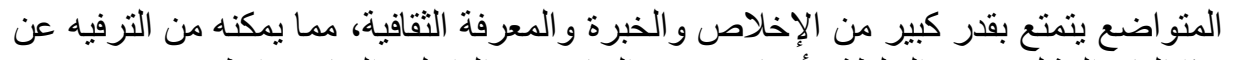
هذا القائد المنقل بهموم السلطة و أعباء منصبه القيادي في الداخل و الخارج. انظر :

. E. Sciarrino 2006, 449-469, esp. 265 -

- Cic., Brut., 75.7^

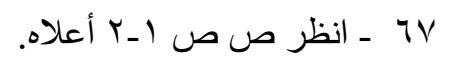

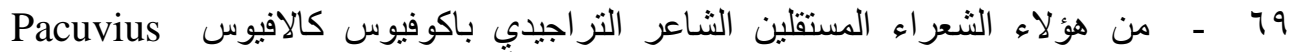

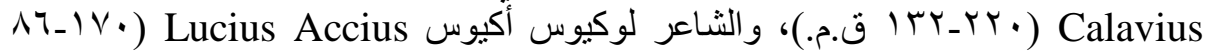

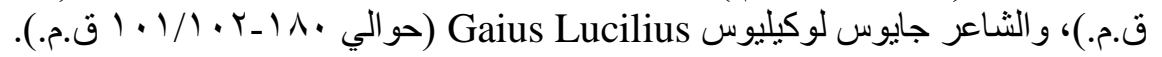




\section{التطورات السياسية وانعكاساتها على أشعار إنيوس الارامية والملحمية}

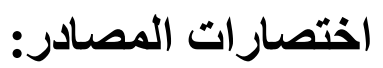

- Aurel. Vict., De Vir. Illus., = Aurelius Victor, De Viris Illustribus.

- Cic., Brut., $\quad$ = Cicero, Brutus.

- Cic., De Nat. Deor., = Cicero, De Natura Deorum.

- Cic., In Verr., $\quad$ = Cicero, In Verrem.

- Cic., Pro Arch., = Cicero, Pro Archia .

- Cic.,Tusc., Disp., = Cicero, Tusculanae Disputationes.

- Enn., Ann., = Ennius, Annales.

- Enn., Epig., $\quad=$ Ennius, Epigrammata .

- Enn., Fab. Praet., Ambr., = Ennius, Fabulae Praetextae, Ambracia.

- Enn., Scip, $\quad=$ Ennius, Scipio .

- Fest., De Sig. Ver., = Festus, De Significatu Verborum.

- Gell., Noct. Att., = Gellius, Noctes Atticae.

- Hom., Il., = Homerus, Ilias.

- Liv., A.U.C., $\quad$ = Livius, Ab Urbe Condita .

- Macr., Sat., $\quad$ = Macrobius, Saturnalia .

- Naev., Var., $\quad=$ Naevius, Varia .

- Plin., Nat. Hist., $\quad=$ Plinius, Naturalis Historia.

- Plut., Marc., $\quad$ = Plutarchus, Marcellus.

- Poly., Hist., $\quad$ = Polybius, Historiae . 
- Sil. Ital., Pun., = Silius Italicus, Punica .

- Suet., De Illus. Gram.,= Suetonius, De Illustribus

\section{Grammaticis.}

- Val. Max., Fac. et Dic. Mem., = Valerius Maximus, Facta et Dicta Memorabilia.

- Verg., Aen., = Vergilius, Aeneis.

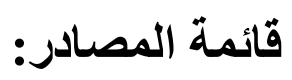

- Aurelius Victor, De Viris Illustribus urbis Romae, F. Pichlmayr, Leipzig, Teubner, 1911 .

- Cicero, The speeches : Pro Archia Poeta, Post Reditum in Senatum, Post Reditum ad Quivites, De Domo Sua, De Haruspicum Responsis- Pro Plancio, with an English trans. by N. H. Walts, London, 1923.

- ------, Brutus, with an English trans. by G. L. Hendrickson, Cambridge, 1969.

- -------, In Verrem, trans. by T. N. Mitchell, Warminster, 1986.

- ------, De Natura Deorum, trans. with introd. and explanatory notes by P.G. Walsh, New York, 1997.

- ------, Tusculanae Disputationes, Cicero on the Emotions, trans. by M. Graver, Chicago, 2002.

- Ennius, Annals of Quintus Ennius, ed. by E. M. Steuart, New York, 1976. 


\section{التطورات السياسية وانعكاساتها على أشعار إنيوس الارامية والملحمية}

- -------, and Caecilius, Remains of Old Latin, vol. 1, ed. and trans. by E. H. Warmington, L.C.L. London, 1988.

- Festus, Sexti Pompei, Festi De verborum significatu quae supersunt cum Pauli epitome, edidit W. M. Lindsay, Teubner, 1965 repr.

- Gellius, The Attic Nights, with an English trans. by J. C. Rolfe, Cambridge, 1998

- Homerus, Iliad, vol. I, trans. by A. T. Murray, rev. by F. Wyatt, L.C.L, 1999.

- Livius Andronicus, Naevius, Pacuvius, Accius, Remains of Old Latin, vol. II, trans. by E. H. Warmington, L.C.L, 1936.

- Livy, History of Rome, vol.3, trans. by B. O. Foster, Cambridge, 1984.

- Macrobius, Saturnalia, Books 1-2, ed. and trans. by R. A. Kaster, L.C.L, 2011.

- Pliny, Natural History, with an English trans. by H. Rackham, Cambridge, 1983.

- Plutarch, Makers of Rome, nine lives : Coriolanus, Fabius Maximus, Marcellus, Cato the Elder, Tiberius Gracchus, Gaius Gracchus, Sertorius, Brutus, Mark Antony, trans. with an introd. by I. Scott-Kilvert, Baltimore, Penguin Books, 1968.

- Polybius,The Histories, with an English trans. by W. R. Paton, London, 1927.

- Silius Italicus, Punica, vol. 2, with an English trans. by J. D. Duff, Cambridge, 1996. 


\section{فاتن عثمان}

- Suetonius, De Grammaticis et Rhetoribus, ed. with a trans., introd. and comment. by R. A. Kaster, Oxford, 1997.

- Valerius Maximus, Factorum ac dictorum memorabilium, 2 vols., ed. and trans. by D. R. Shackleton Bailey, Cambridge, 2000.

- Virgil, The Works of Virgil, vol. III, with a comment. by J. Conington and H. Nettleship, New York, 1979 .

$$
\text { اختصارات الدوريات والقواميس: }
$$

- ANRW = Aufstieg und Niedergang der römischen Welt.

- BICS = Bulletin of the Institute of Classical Studies.

- CLAnt = Classical Antiquity.

- $C Q=$ Classical Quarterly.

- TAPhA = Transactions and Proceedings of the American Philological Association.

- OCD = Oxford Classical Dictionary.

\section{قائمة المراجع والدوريات:}

- Acimovic, A. 2007. Scipio Africanus. New York.

- Astin, A. E. 1978. Cato the Censor. Oxford.

- Badian, E. 1972. "Ennius and His Friends." in Ennius. ed. by O. Skutsch. Geneve. 149-208.

- Beard, M. 2007. The Roman Triumph. Harvard University Press.

- Boyle, A. J. 2006. Roman Tragedy. New York. 
التطورات السياسية وانعكاساتها على أثعار إنيوس الدرامية والملحمية

- Conte, G. 1994. Latin Literature: A History. trans. by J. B. Solodow. London.

- Cornell, T. J. 1995. The Beginnings of Rome: Italy and Rome from the Bronze Age to the Punic Wars (c. 1000-264 BC). London, New York.

- El-Nowieemy, M. 2011. "Intellectual and Military Might: The Politics of Learning between Alexandria and Rome." Alexandria and other Centers of Thought in Ancient Egypt. ed. by M. Abdel Nasser and S. Hamouda. Alexandria. 69-84.

- ----o- r.1r. "Hellenism, Alexandrianism, and Roman Enlightenment." Proceedings of the International Conference on Alexander, the Greek Cosmos-System and Contemporary Global Society. Thessaloniki, Greece. 403-415. Accessed at 17/ 2/ 2015.

- Erasmo, M. 2004. Roman Tragedy: Theatre to Theatricality. University of Texas Press.

- Fantham, E. 1999. Roman Literary Culture: From Cicero to Apuleius. Johns Hopkins University Press.

- Flower, H. I. 1995. "Fabulae Praetextae in Context: When Were Plays on Contemporary Subjects Performed in Republican Rome?" $C Q$, 45: 170-190.

- ----o. r... "The Tradition of the Spolia Opima: M. Claudius Marcellus and Augustus." CLAnt 19: 34-64.

- Gildenhard, I. 2003. "The 'Annalist' Before the Annalists: Ennius and his Annales." in Formen römischer Geschichtsschreibung von den Anfängen bis Livius: Gattungen, Autoren, Kontexte. ed. by U. Eigler, U. Gotter, N. Luraghi and U. Walter. Darmstadt. 93 - 114. 


\section{فاتن عثمان}

- Goldberg, S. M. 1974. "Poetry, Politics, and Ennius." TAPhA 119: 247-261. 1990. Epic in Republican Rome. Oxford.

- -- r... . "The Early Republic: The Beginnings to 90 BC." in A Companion to Latin Literature. Oxford. 15-30.

- Gruen, E. S. 1990. Studies in Greek Culture and Roman Policy. Leiden.

- 199r. Culture and National Identity in Republican Rome. London.

- Habinek, T. N. 1998. The Politics of Latin Literature: Writing, Identity, and Empire in Ancient Rome. Princeton, Princeton University Press.

- Horsfall, N. 1976. "The Collegium Poetarum." BICS 23: 7995 .

- Jocelyn, H. D. 1972. "The Poems of Quintus Ennius." ANRW 1: $987-1026$.

- Lee, M. O. 1979. Fathers and Sons in Virgil's Aeneid: Tum Genitor Natum. New York.

- Platner, S. B. 1929. A Topographical Dictionary of Ancient Rome. completed and rev. by Th. Ashby. London, Oxford University Press.

- Richardson, L. 1992. A New Topographical Dictionary of Ancient Rome. Baltimore, London.

Rose, H. J. 1996 repr. Handbook of Latin Literature: From the Earliest Times to the Death of ST. Augustine. London.

- Rüpke, J. 2006. "Ennius' Fasti in Fulvius' Temple: Greek Rationality and Roman." Arethusa 39: 489-512. 
التطورات السياسية وانعكاساتها على أثعار إنيوس الدرامية والملحمية

- Sciarrino, E. 2004. "Putting Cato the Censor's Origines in Its Place." CLAnt 23: 323-357.

Y.. ฯ. "The Introduction of Epic in Rome: Cultural

Thefts and Social Contests." Arethusa 39: 449-469.

- Skutsch, O. 1944. "Enniana I." CQ, 38: 79-86.

- ------ 197r. “Enniana V.” CQ, 57: 89-100.

- Taplin, O. 2000. Literature in the Roman World. Oxford.

- Toohey, P. 2007. Melancholy, Love, and Time: Boundaries of the Self in Ancient Literature. University of Michigan Press.

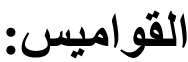

- Oxford Classical Dictionary 2012. ed. by S. Hornblower, A. Spawforth and E. Eidinow. Oxford.

- The Oxford Companion to Classical Literature 2011. ed. by M. C. Howatson. Oxford.

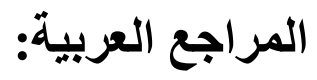

ـ شعر اوي، عبد المعطي 999 1. النقد الأدبي عند الإغريق والرومان. مكتبة الأنجلو المصرية، القاهرة.

ـ عتمان، أحمد 919 أـ الأدب اللاتيني ودوره الحضاري حتى نهاية العصر الذهبي. عالم المعرفة، العدد إـا، الكويت. 